\title{
A Computer Model of Oxygen Dynamics in the Cortex of the Rat Kidney at the Cell-Tissue Level
}

\author{
Vivien Aubert, Jacques Kaminski, François Guillaud, Thierry Hauet ${ }^{\mathbb{D}}$ and Patrick Hannaert *(D) \\ INSERM U1082-IRTOMIT, 86000 Poitiers, France; aubert_vivien@yahoo.fr (V.A.); \\ jacques.kaminski@gmail.com (J.K.); fguillaud@gmail.com (F.G.); thierry.hauet@gmail.com (T.H.) \\ * Correspondence: patrick.hannaert@univ-poitiers.fr; Tel.: +33-5-4944-4954
}

Received: 31 August 2019; Accepted: 5 December 2019; Published: 11 December 2019

check for updates

\begin{abstract}
The renal cortex drives renal function. Hypoxia/reoxygenation are primary factors in ischemia-reperfusion (IR) injuries, but renal oxygenation per se is complex and awaits full elucidation. Few mathematical models address this issue: none captures cortical tissue heterogeneity. Using agent-based modeling, we develop the first model of cortical oxygenation at the cell-tissue level (RCM), based on first principles and careful bibliographical analysis. Entirely parameterized with Rat data, RCM is a morphometrically equivalent $2 \mathrm{D}$-slice of cortical tissue, featuring peritubular capillaries (PTC), tubules and interstitium. It implements hemoglobin $/ \mathrm{O}_{2}$ binding-release, oxygen diffusion, and consumption, as well as capillary and tubular flows. Inputs are renal blood flow RBF and $\mathrm{PO}_{2}$ feeds; output is average tissue $\mathrm{PO}_{2}\left(\mathrm{tPO}_{2}\right)$. After verification and sensitivity analysis, $\mathrm{RCM}$ was validated at steady-state $\left(\mathrm{tPO}_{2} 37.7 \pm 2.2 \mathrm{vs} .36 .9 \pm 6 \mathrm{mmHg}\right)$ and under transients (ischemic oxygen half-time: $4.5 \pm 2.5$ vs. $2.3 \pm 0.5 \mathrm{~s}$ in situ). Simulations confirm that $\mathrm{PO}_{2}$ is largely independent of RBF, except at low values. They suggest that, at least in the proximal tubule, the luminal flow dominantly contributes to oxygen delivery, while the contribution of capillaries increases under partial ischemia. Before addressing IR-induced injuries, upcoming developments include ATP production, adaptation to minutes-hours scale, and segmental and regional specification.
\end{abstract}

Keywords: kidney; oxygen; renal cortex; peritubular capillary; proximal tubule; rat; hemoglobin; oxygen consumption; Na reabsorption; agent-based model

\section{Introduction}

Renal hypoxia is considered a common root of acute and chronic kidney diseases [1,2]. In transplantation, the unavoidable ischemia-reperfusion sequence (IR) is involved in short and long-term graft dysfunctions and injuries (IRI) [3-5]. Paradoxically, the kidney can sustain hypoxic/ischemic periods up to tens of hours [6], but it is also exquisitely sensitive to oxygenation/perfusion defaults $[7,8]$, to the point that ischemia-induced renal failure is much more frequent than in other organs [9]. Renal oxygenation has been puzzling renal physiologists for decades, and still does $[1,7,10,11]$. Sixty years after the first evidence of oxygen decrease from the cortex to the inner medulla, numerous features have been experimentally unraveled [11,12]. In addition to the cortico-medullary $\mathrm{PO}_{2}$ gradient $(40-60 \mathrm{mmHg}$ in the cortex to $5-25 \mathrm{mmHg}$ in the medulla), they include the arteriovenous (AV) diffusive oxygen shunting, a low oxygen extraction ratio (10-15\%), a luxurious perfusion amounting to $10 \%$ of cardiac output per kidney-required for an efficient filtration function-and an oxygen consumption driven by glomerular filtration: the more it filters, the more oxygen the kidney consumes for $\mathrm{Na}^{+}$reabsorption $[13,14]$ (for a quantitative review of basal oxygen consumption, see [15]). Moreover, the kidney exhibits intricate anatomical and metabolic specificities, at the regional and segmental levels $[16,17]$, coupled to a complicated glomerulo-tubulo-vascular organization and regulations [18], which altogether appear to dictate tissue-level oxygen-related 
heterogeneities [19]. This complexity pushed physiologists to resort to mathematical modeling and computer simulation (MS), as a complement to the experimental approaches [10,20-23].

Renal oxygen distribution started to be addressed under the MS angle in the late 90's [12,20]. The AV oxygen shunt has been long hinted and its mathematical descriptions are based on careful anatomic determinations. However, its physiological relevance and quantification remain debated [23-26]. Finally, oxygen distribution within the medulla, with its countercurrent system and complex organization, has been modeled with attention and a great level of histological detail [27-30].

Conversely, oxygen distribution in the cortex has been addressed only lately, in the mid-2010's. Likely, the urine concentration and $\mathrm{NaCl}$ reabsorption role of the medulla have somewhat eclipsed the cortex [30,31]. Further, since the cortex is highly perfused and exhibits $\mathrm{PO}_{2}$ levels similar to other organs' (30-60 mmHg), its oxygenation has been considered unlimited. Finally, the cortical apparent disorder (cortical tubular labyrinth, entangled with the peritubular capillary network), is less amenable to geometric treatment than the highly organized medullary regions [32].

Recently though, a few modeling studies of oxygen use and distribution in the renal cortex have been proposed. These MS studies follow either one of two conceptual lines: one focuses on nephron segmentation and epithelial polarity and transport, while the other ignores epithelial "details" but integrates vascular anatomical features to describe delivery and consumption all along the renal vascular tree. In the tubule-centered line, expanding the proximal constructs by Weinstein and et al. [33,34], Layton and et al. provide a detailed description, along the proximal tubule, of oxygen consumption in relation to epithelial transporters [22,35]. However, they ignore both tissue heterogeneity and oxygen availability. Conversely, in the vascular-centered line, Lee and et al. propose an elaborate model of oxygen transport and consumption in the rat renal cortex, based upon a previous model of AV diffusional shunting (see above). This top-down anatomically-based model predicts average tissue and micro-vascular $\mathrm{PO}_{2}$ [10].

From a pathophysiological standpoint, renal IRI has been shown to develop in specific areas, such as the deep cortex, and tissue regions in the kidney, tubular segments, and cell-types exhibit marked differences in terms of lesional or adaptive responses to alterations in oxygen levels [8,36,37]. Moreover, the ultimate sensors and victims of ischemia and/or reperfusion are parenchymal and mesenchymal cells, including epithelial, capillary, and interstitial cells, as reflections of renal tissue heterogeneity. Thus, an informed description of the mechanisms and specificities of renal cortical oxygenation at the histological level under normal conditions appears as a minimal prerequisite to understand, quantify, and ultimately to correct the central role of oxygen-related dysfunctions. However, this is bound to be an ab initio endeavor, since no MS study at the cortical cell-issue level has been proposed yet.

The objective of the study is as follows., As a first step toward a realistic description of kidney IR events, we present here the development and validation of a computer model of renal cortical oxygenation, at the cell-tissue level. In order to address the discreteness and heterogeneity of cellular, tubular and tissue components, we use agent-based modeling. In order to assure internal consistency and to rule out inter-species differences, the model is specifically parameterized for the Rat. Including the main biophysical features of oxygen transport, exchange, diffusion, and consumption, within an idealized histological tissue slice, it is a dynamic construct, able to delineate transients as well as steady-state $\mathrm{PO}_{2}$.

\section{Methods}

\subsection{Bibliographical Analysis and Data Extraction}

A thorough bibliographical search and analysis was performed for the extraction of Rat kidney data (anatomical and geometrical, functional and biochemical), quantitative and qualitative. We focused on healthy, adult male Rats $\sim 70 \%$, the rest female); only studies/data relating to animals older than 12 weeks (or with a bodyweight $>180 \mathrm{~g}$ ) were considered. More than 800 Rat-related references

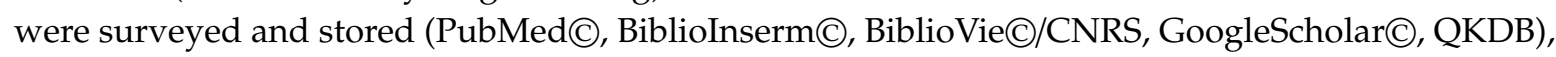


and about 160 original were selected and used. The species targeted in the study is the Rat (Rattus norvegicus), which in our experimental studies corpus (kidney, cortex, tubule, flow) is dominated by the Sprague-Dawley and Wistar strains (about half of the studies), followed by the Münich (Münich-Wistar and Münich Frömter), Dahl, Lewis and Wistar-Kyoto strains. For simplicity and because the different parameters required by the model are not available for all those strains, no attempts were made to distinguish between those strains.

\subsection{Agent-Based Modeling with NetLogo@}

Histological elements such as tubules, capillaries, and cells are discrete and discontinuous elements. As opposed to more conventional equation-based formalism $[27,28,33]$, they are best described by the computer "agent" concept, as implemented in agent-based modeling, ABM [38,39]. Agents are autonomous, "reactive" objects, dynamically interacting with each other, according to a set of rules. They are defined by variables and functions which allow them, at each execution step, to modify their own variables as well as those of other agents, including those constituting their environment. We used NetLogo $@$ (version 6.10), a free ABM programming language and modeling platform, which presents multiple advantages, including power and versatility. Originally designed for educational purposes, NetLogo is now widely used for research as well. For detailed presentations of ABM and NetLogo, see [38-40].

In NetLogo, patches are a special type of agent that is fixed, unable to move, but otherwise, possess all agent properties. Since tissue structure is fixed in our rat renal cortical model (RCM), we use "patches": thus, we will use "patch" to refer to model elements.

\subsection{The Cortical Tissue Model for the Rat Kidney}

The RCM is an idealized slab of the cortex. Figure 1 illustrates the mapping of the four principal cortical histological components into NetLogo, using fixed agents, the so-called "patches" (mobile cell elements such as macrophages are currently not represented). Vascular patches (PTC), correspond to peritubular capillaries, including their endothelial layer (not represented, because typical height is $<1.0 \mu \mathrm{m}$ ). PTC were axially perfused with post-glomerular, capillary "blood". Note that erythrocytes are not individualized, but idealized as "mixed" with the plasma. Model tissue receives oxygen input via "blood" perfusion of PTC patches. Epithelial patches (EPI) roughly correspond to proximal cells, and their various cell surfaces (brush-border, lateral, basal) are attributed values from detailed morphometric determinations [41,42]. Luminal patches (LUM) form the tubule lumen. One important feature of RCM, overlooked in other studies, is the implementation of such tubular patches and related perfusion. Interstitial patches (INT) correspond to the mesenchymatous interstitium, extracellular matrix, and interstitial cells.

RCM tissue dimensions are $320 \mu \mathrm{m} \times 320 \mu \mathrm{m}$, subdivided into 1024 square patches $\left(10 \times 10 \mu \mathrm{m}^{2}\right)$. In order to define oxygen concentration, exchange surfaces, as well as orthogonal capillary and tubular feeding volumetric flows, a thickness of $10 \mu \mathrm{m}$ was chosen, close to epithelial cells and luminal dimensions (default patch volume: $1000 \mu \mathrm{m}^{3}$, or $\mathrm{fL}$ ). Total tissue volume is $\sim 1.0 \mathrm{~nL}$ (1024 fL). Additional simplificationse: (i) brush-border height isaggregated to the lumen $\left(\mathrm{BBH}^{\circ}=4.3 \mu \mathrm{m}\right.$, SM1-Table S3a); (ii) glomerules ( $4 \% v / v$ of the cortical tissue) are considered inexistent at RCM scale (in-between two cortical radial arteries and their glomerular tufts); (iii) non-capillary vessels $(\sim 15 \% v / v)$ are ignored, as well as lymphatics $(2 \% v / v ;[41,43])$.

Patches and model variables: patches possess their own variables, including oxygen diffusivity D (patch units, PU: $\mu^{2} / \mathrm{ms}$ ), volume ( $\mu^{3}$ or $\mathrm{fL}$ ), oxygen content (amoles), oxygen concentration (amol/patch, or $\mu \mathrm{mol} / \mathrm{L}$ ) and oxygen partial pressure $(\mathrm{mmHg}$ ), in addition to house-keeping (all patches) and transport-related oxygen consumption (epithelial patches only). Model and patches also handle global variables, including the number of nephrons, volumetric flows (e.g., RBF and single-nephron glomerular filtration rate, SNGFR). 


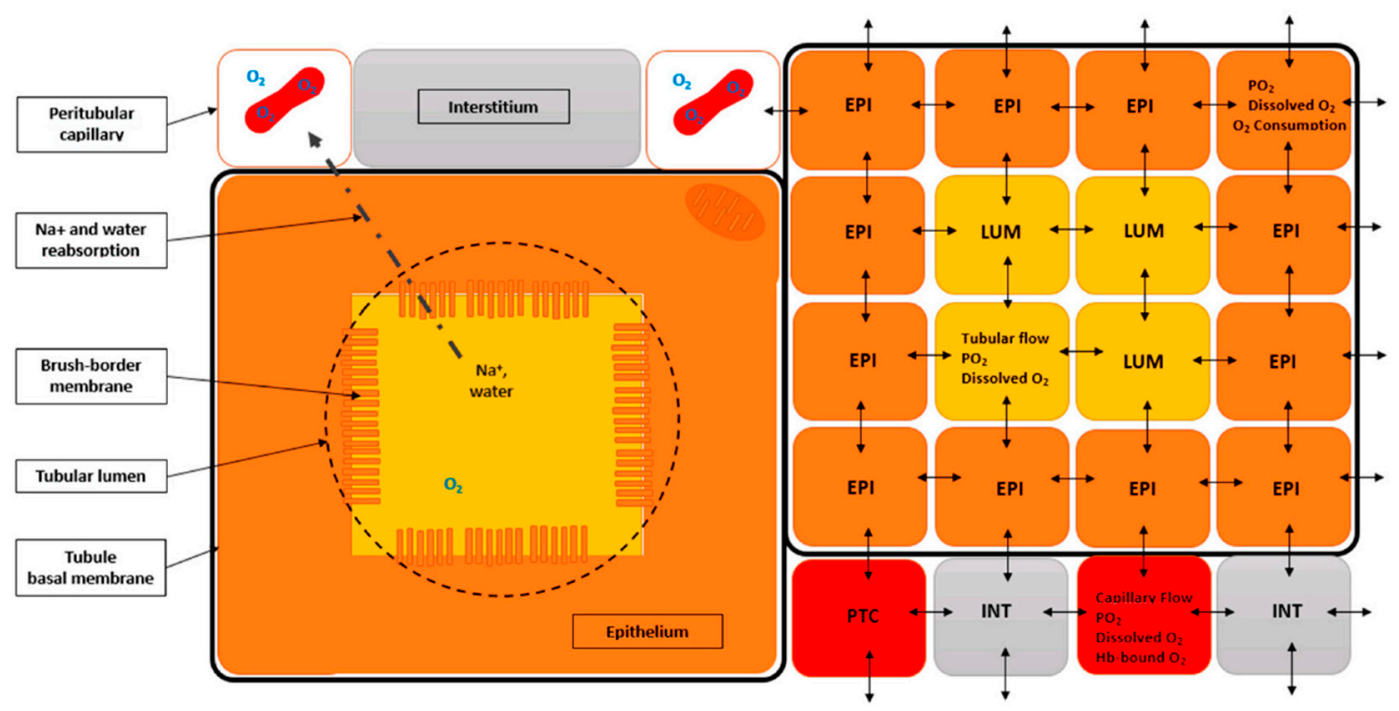

Figure 1. Schematic illustration of renal cortical tissue in rat renal cortical model (RCM). (Left) Histological components that are implemented in the model. Peritubular capillaries (white squares), which contain red blood cells, oxygen, and hemoglobin $(\mathrm{Hb})$. Tubular epithelium (orange square), with its brush-border membrane; nuclei are not represented, but one $\mathrm{O}_{2}$-consuming/ATP-producing mitochondria is symbolized in the upper right corner. Tubular lumen (yellow square), containing glomerular ultrafiltrate (including water, sodium, oxygen); the point-dotted arrow symbolizes tubular reabsorption from the lumen to one peritubular capillary, an ATP/O 2 consuming process. Interstitium (grey rectangle): only "fixed" elements are considered in the current model, thus interstitial cellular elements, such as resident fibroblasts and macrophages, are not represented, although their oxygen consumption is accounted for in model calculations. The square thick black line represents the tubule basal membrane. (Right) RCM tissue implementation with NetLogo. This section shows how the histological components are mapped within NetLogo, the ABM software used (nb: we use only fixed agents, called "patches" in NetLogo). Four different types of patches are defined: (i) peritubular capillaries (PTC), or peritubular capillary patches, characterized by their flow rate (transverse, not represented), $\mathrm{PO}_{2}, \mathrm{Hb}$ content, oxygen content, and concentration, etc (erythrocytes are not represented and hemoglobin is considered homogeneously distributed within PTC); (ii) epithelial patches (EPI), or tubular epithelial patches, characterized by similar $\mathrm{O}_{2}$-related variables (no $\mathrm{Hb}$, no flow), (iii) luminal patches (LUM), or luminal patches (flow rate, $\mathrm{O}_{2}$-related variables, no $\mathrm{Hb}$, no consumption), and (iv) INT, or interstitial patches (same variable types as EPI). Importantly, all patch-types have their own oxygen diffusion coefficient: double-headed arrows symbolize inter-patches oxygen diffusive exchanges.

Model structure and geometry: from bibliographical analysis and histological slices from the laboratory, we devised several "cortical tissues": their detailed characteristics are presented in Supplementary Materials (SM2-Table S1). The main morphometric features are the capillary density and the proximal tubule dimensions, both expected to influence oxygen supply and consumption. The outer tubular radius (orTub) ranges 15-30 $\mu \mathrm{m}$ (see SM1-Table S3a), and tubules represent $~ 60-80 \%$ $v / v$ of the cortex. The capillary density ranges $250-1110 \mathrm{~mm}^{-2}$ (capillary/tubule ratio ranges 1.1-2.2)

In order to quantify the influence of these indexes on model output, we constructed six tissue variants for RCM, featuring two radius (orTub $=20 \mu \mathrm{m}$ or $25 \mu \mathrm{m}$ ), combined with three capillary/tubule ratio $(\mathrm{Nc} / \mathrm{Nt}$ ratio $=1.0,1.5$ and 2.0): the reference, base-case tissue is the "1540", for $1.5 \mathrm{Nc} / \mathrm{Nt}$ and $40 \mu \mathrm{m}$ orTub. Model tissues were edited using a customized NetLogo program (a modification by one of us, VA, of the "NetLogo Pac-Man Level Editor", U. Wilenski (2003), available in NetLogo Models Library).

Finally, for proper oxygen diffusion (Fick's first diffusion law), the effective exchange surface area (ESA) is a key morphometric aspect: e.g., the brush-border membrane for lumen-epithelial contacts 
augments considerably ( 20-fold) the lumen-to-epithelium contacts [41]. Because ESA varies according to tissue components involved, we defined adjusting factors for all exchanging patch-type pairs in the diffusion routine: the default ESA $\left(100 \mu \mathrm{m}^{2}\right)$ is multiplied the corresponding patch-to-patch factor (Equation (16); see SM1-Table S3b).

\subsection{Units, Inputs/Outputs, Parameters and Variables}

Units and normalization: for the whole kidney, we normalize eligible variables to gram of kidney weight (gkw), whereas in RCM we express most variables either per nephron (e.g., volumetric flows in $\mathrm{nL} / \mathrm{min}$ ), or per patch type. For $\mathrm{O}_{2}$ consumption, we equate "mmol. (min. $\left.10^{3} \mathrm{gkw}\right)^{-1}$ " to "mM/min" (or mmol.(L.min) ${ }^{-1}$ ), considering kidney tissue density equal to $1 \mathrm{~mL} / \mathrm{gkw}$ [42]. Further, because we address either the whole-kidney, the cortex itself, or patches within the model, in order to

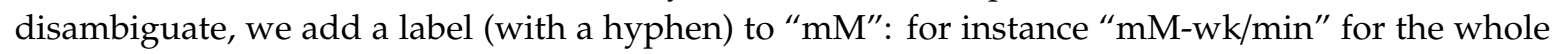
kidney or "mM-ctx/min" for the cortex. For patches, we refer to their "specific" consumption (e.g., $\mathrm{mM}-\mathrm{EPI} / \mathrm{min}$ ). Within RCM, units are adapted to patch and time dimensions (patch units, PU): $\mu \mathrm{m}$, $\mathrm{ms}$, amol and $\mathrm{mmHg}\left(1 \mathrm{amole} / 1000-\mu \mathrm{m}^{3}\right.$ patch $=1 \mu \mathrm{mol} / \mathrm{L}$ or $\left.\mu \mathrm{M}\right)$.

Model inputs/outputs, parameters, and variables: model inputs are external (or independent) variables that drive model outputs, given a parametric configuration. The main model inputs are renal blood flow (RBF) and feeding $\mathrm{PO}_{2}$ (capillaries and tubules). Inputs can be fixed for the entire simulation, or changed at run-time. Model outputs are dependent variables; the main output is the (average) cortical oxygen partial pressure, because experimentally it is the measured variable (in some studies, the vascular $\mathrm{PO}_{2}$ is determined). As mentioned, each patch has its own set of variables, among which $\mathrm{O}_{2}$ amount is the state variable. This allows for monitoring local and average $\mathrm{PO}_{2}$ for epithelial, capillary, interstitial, or luminal compartments. Finally, we define independent parameters, the value of which conditions other (dependent) parameters.

\subsection{Model Equations}

We implemented dynamic descriptions of perfusion, hemoglobin- $\mathrm{O}_{2}$ binding/release, diffusion, and consumption, in order to determine levels of oxygen throughout the model and the different patch types.

\subsubsection{Equations for Perfusion and Volumic Flows}

(1) “Cortical blood flow:

$$
\mathrm{CBF}=\mathrm{RBF} \cdot \mathrm{frCBF}
$$

where CBF, model cortical blood flow ( $\mathrm{mL} \cdot \mathrm{min}^{-1} \cdot \mathrm{gkw}^{-1}$; FU, flow units), RBF, renal blood flow: $\mathrm{FU}$ (model input, controlled from the model interface), frCBF, fractional cortical blood flow (see text, above; no unit).

(2) Operational nephrons:

$$
\mathrm{OpNe}=\mathrm{N}_{\text {tot }} \cdot \text { frNCtx }
$$

where OpNe is the functioning nephron density: $\mathrm{gkw}^{-1}, \mathrm{~N}_{\text {tot }}$ is total nephron density in the kidney: $\mathrm{gkw}^{-1}$, frNCtx is fraction of operational nephrons in the model(no unit).

(3) Single nephron glomerular blood flow:

$$
\mathrm{SNGBF}=10^{6} \cdot \frac{\mathrm{CBF}}{\mathrm{OpNe}}
$$

where SNGBF is single nephron glomerular blood flow ( $\mathrm{nL} / \mathrm{min} ; 10^{6}$ converts $\mathrm{mL}$ to $\mathrm{nL}$ ). Please note that the flow unit now refer to a single nephron. 
(4) Single nephron efferent arteriolar blood flow:

$$
\mathrm{SNEABF}=\mathrm{SNGBF} \cdot[1-F F \cdot(1-H t a)]
$$

where SNEABF is the single nephron efferent arteriolar blood flow (nL/min), FF is the filtration fraction: no unit, Hta is the arterial hematocrit (no unit).

(5) Single nephron glomerular blood flow,

$$
\mathrm{SNGFR}=\mathrm{SNGBF}-\mathrm{SNEABF}
$$

where SNGFR is the single nephron glomerular blood flow (nL/min).

(6) "Single nephron" absolute proximal reabsorption:

$$
\mathrm{SNAPR}=\text { frPR } . \mathrm{SNGFR}
$$

where SNAPR is the single nephron absolute proximal reabsorption $(\mathrm{nL} / \mathrm{min}), \mathrm{frPR}$ is the fractional proximal reabsorption (no unit).

(7) Capillary volumic flow:

$$
\mathrm{CVF}=\frac{\mathrm{SNEABF}}{\mathrm{fCapBr}}+0.5 \cdot \frac{\mathrm{SNAPR}}{\mathrm{fCapBr}}
$$

where CVF, capillary volumic flow (nL/min), fCapBr, capillary branching factor (no unit). The capillary branching factor $(\mathrm{fCapBr}=6)$ corresponds to the average number of capillaries derived from the efferent arteriole (calculated from [44]).

(8) Tubular volumic flow:

$$
\mathrm{TVF}=\mathrm{SNGFR}-0.5 \text {.SNAPR }
$$

where TVF is the tubular volumic flow $(\mathrm{nL} / \mathrm{min})$.

2.5.2. Equations for Epithelial Transport $\left(\mathrm{Na}^{+}\right.$, water)

(1) Single nephron $\mathrm{Na}^{+}$filtered load:

$$
\text { SNFLNa }=10^{6} \text {.SNGFR .Nap }
$$

where SNFLNa is the single nephron $\mathrm{Na}^{+}$load (amol/min; $10^{6} \mathrm{pmol}$ to amol), Nap, plasma sodium concentration $(\mathrm{mmol} / \mathrm{L})$.

(2) $\mathrm{Na}^{+}$transport (reabsorption):

$$
\mathrm{TNa}=\text { frPR } . \text { SNFLNa } \cdot \frac{1}{12} \cdot \frac{10}{\text { TubLength }}
$$

$\mathrm{TNa}(\mathrm{amol} / \mathrm{min})$ is the sodium transport for one epithelial patch in a tubule section $(10 \mu \mathrm{m}$-thick and TubLength $\mu \mathrm{m}$-long); $1 / 12$ is the number of EPI patches per tubule section, it scales local reabsorption to one patch, for tissues with $40 \mu \mathrm{m}$ outer diameter (orTub; = see Figure 1, right); in $50 \mu \mathrm{m}$ orTub, the scaling factor is $1 / 16$; frPR, fractional proximal reabsorption (no unit).

\subsubsection{Equations for Capillary and Tubular Inputs (PTC, LUM patches)}

Capillary and tubular convective oxygen delivery (and removal) by perfusion are modeled using a volume renewal factor, and used to update oxygen content The latter is calculated as tick duration divided by the volumic residence time. 
(1) Capillary flow factor:

$$
\mathrm{CFF}=\frac{1}{6 \cdot 10^{-2}} \quad \cdot \frac{\text { tickduration }}{\frac{\text { Vcap }}{C V F}}
$$

where CFF is the capillary flow factor (no unit), tickduration in ms (default $1 \mathrm{~ms}$ ), CVF is the capillary volume flow (nL/min),

Vcap is the capillary patch (PTC) volume: $\mu \mathrm{m}^{3}\left(1 / 6.10^{-2}\right.$ converts $\mu \mathrm{m}^{3}$ to $\mathrm{nL}$ and $\mathrm{min}$ to $\mathrm{ms}$ ).

(2) Capillary oxygen renewal (PTC patches):

$$
\mathrm{qO}_{2}(\mathrm{t}+1)=\mathrm{qO}_{2}(\mathrm{t})-\mathrm{CFF} . \mathrm{qO}_{2}(\mathrm{t})+\mathrm{CFF} . \mathrm{qO}_{2}(\text { PTC_input })
$$

where $\mathrm{qO}_{2}(\mathrm{t}+1), \mathrm{qO}_{2}(\mathrm{t})$ are the PTC patch oxygen content (amol), at tick +1 and current tick, respectivley, $\mathrm{qO}_{2}\left(\mathrm{PTC} \_\right.$input) is the PTC oxygen feed (amol), converted from model interface PTC $\mathrm{PO}_{2}$ input.

(3) Tubular flow factor (TFF):

$$
\mathrm{TFF}=\frac{1}{4} \cdot \frac{1}{6 \cdot 10^{-2}} \quad \cdot \frac{\text { tickduration }}{\frac{\text { Vlum }}{\text { TVF }}}
$$

where TFF is the tubular flow factor (no unit), TVF is the tubular volume flow (nL/min), Vlum is the luminal patch volume ( $\mu \mathrm{m}^{3}$; conversion factor as above); $\frac{1}{4}$ corresponds to 4 LUM patches per tubule section (see Figure 1) (1/9 for tissues with $50 \mu \mathrm{m}$ tubule diameter, see tissue variants in SM2).

(4) Luminal oxygen renewal (LUM patches):

$$
\mathrm{qO}_{2}(\mathrm{t}+1)=\mathrm{qO}_{2}(\mathrm{t})-\mathrm{TFF} . \mathrm{qqO}_{2}(\mathrm{t})+\mathrm{TFF} . \mathrm{qO}_{2}\left(\mathrm{LUM} \_ \text {input }\right)
$$

where $\mathrm{qO}_{2}(\mathrm{t}+1), \mathrm{qO}_{2}(\mathrm{t})$ are the LUM patch oxygen content (amol), at tick +1 and current tick, respectivley, $\mathrm{qO}_{2}$ (LUM_input) is the LUM oxygen feed (amol), converted from model interface LUM $\mathrm{PO}_{2}$ input.

\subsubsection{Equations for Hemoglobin (PTC Patches)}

Equations for hemoglobin- $\mathrm{O}_{2}$ association/ dissociation reactions are taken from [45].

(1) Rate equations and associated equations

$$
\begin{gathered}
\text { nHill }=\frac{2.635 \cdot\left(\mathrm{HbO}_{2} \%\right)^{2}-274.042 \cdot \mathrm{HbO}_{2} \%}{\left(\mathrm{HbO}_{2} \%\right)^{2}-104.1 \cdot \mathrm{HbO}_{2} \%-31.32} \\
\mathrm{k}^{\prime} \mathrm{c}=6.325 \cdot \mathrm{e}^{\left(0.011537 \cdot \mathrm{HbO}_{2} \%\right)^{2.88697}}
\end{gathered}
$$

NB: after proper verifications, to reduce calculation load on NetLogo, Equation (16) was replaced in RCM by a three-parameters regression obtained from Xuru-online (http://www.xuru.org):

$$
\begin{gathered}
\mathrm{k}^{\prime} \mathrm{c}=0.04525 . \mathrm{HbO}_{2} \%^{2.8222}+5441.2829\left(\mathrm{R}^{2}=0.953\right) \\
\mathrm{JdissHb} \%=\mathrm{k}^{\prime} \mathrm{c} \cdot\left(\alpha \cdot \mathrm{P}_{50}\right)^{\mathrm{nHill}} \cdot \mathrm{HbO}_{2} \% \\
\mathrm{JassoHb} \%=\mathrm{k}^{\prime} \mathrm{c} \cdot\left(\alpha \cdot \mathrm{P}_{\mathrm{O} 2}\right)^{\mathrm{nHill}} \cdot \mathrm{HbO}_{2} \% \\
\mathrm{HbO}_{2} \%(\mathrm{t}+1)=\mathrm{HbO}_{2} \%(\mathrm{t})-\mathrm{JdissHb} \%+\mathrm{JassoHb} \% \\
\text { JdissHb }=0.01 . \mathrm{JdissHb} \% . \mathrm{Hbt}
\end{gathered}
$$




$$
\mathrm{JassoHb}=0.01 . \mathrm{JassoHb} \% . \mathrm{Hbt}
$$

where $\mathrm{n}_{\mathrm{Hill}}$ is the Hill's cooperativity index (no unit; [45]), $\mathrm{HbO}_{2} \%$ is the $\mathrm{Hb} \%$ saturation, $\mathrm{k}^{\prime} \mathrm{c}$ is the "pseudo-velocity parameter" (mM.ms ${ }^{-1}$, see [45]), $\alpha$ is the oxygen solubility coefficient in plasma: $\mu \mathrm{M} / \mathrm{mmHg}, \mathrm{P}_{50}$ is the half-saturation oxygen pressure of hemoglobin ( $\mathrm{mmHg}$ ), Jdiss $\mathrm{Hb} \%$ is the $\mathrm{Hb}-\mathrm{O}_{2}$ dissociation rate (\%saturation/ms, [45]), Jass $\mathrm{Hb} \%$ is the $\mathrm{Hb}-\mathrm{O}_{2}$ association rate (\%saturation/ms, [45]), Jdiss $\mathrm{Hb}$ is the $\mathrm{Hb}-\mathrm{O}_{2}$ dissociation rate (amol/ms), Jass $\mathrm{Hb}$ is the $\mathrm{Hb}-\mathrm{O}_{2}$ dissociation rate (amol/ms), $\mathrm{Hbt}$ is the monomeric hemoglobin equivalent (amol/patch).

(2) Oxygen balance related to $\mathrm{Hb}-\mathrm{O}_{2}$ association/dissociation:

$$
\mathrm{qO}_{2}(\mathrm{t}+1)=\mathrm{qO}_{2}(\mathrm{t})+4 . \mathrm{JdissHb}-4 . J a s s o H b
$$

with $\mathrm{qO}_{2}(\mathrm{t}+1)$ and $\mathrm{qO}_{2}(\mathrm{t})$, PTC patch oxygen content (amol).

\subsubsection{Equations for Diffusion (All Patch Types)}

We devised a diffusion procedure based on Fick's first law, in which the outgoing amount of oxygen from one given "central" patch " $i$ " toward each one of its four " $j$ " Von Neumann neighbors (north, east, south and west), during one tick, is driven by oxygen concentration, the $10 \mu \mathrm{m}$-distance between two adjacent patch centers, the exchange surface area, and oxygen diffusivity, according to:

$$
\begin{gathered}
\text { Jdiff( }(\mathrm{i} \rightarrow \mathrm{j})=\frac{1}{L} \cdot \operatorname{Dij} . \operatorname{Sij} \cdot\left[0_{2}\right] \mathrm{i} \\
q_{i} \mathrm{O}_{2}(\mathrm{t}+1)=q_{i} \mathrm{O}_{2}(\mathrm{t})+\sum_{\mathrm{j}=\mathrm{n}, \mathrm{e}, \mathrm{s}, \mathrm{w}} \operatorname{Jdiff}(\mathrm{j} \rightarrow \mathrm{i})-\sum_{\mathrm{j}=\mathrm{n}, \mathrm{e}, \mathrm{s}, \mathrm{w}} \operatorname{Jdiff}(\mathrm{i} \rightarrow \mathrm{j})
\end{gathered}
$$

where Jdiff $(j \rightarrow i)($ resp. $(i \rightarrow j))$ is the unidirectional diffusion rate from patch $j$ to patch $i$ (resp. patch $i$ to patch $j ; a m o l / m s), L$ is the patch-to-patch diffusion distance $(\mu \mathrm{m}), D_{i j}$ is the average diffusion coefficient of source and target patches $\left(\mu \mathrm{m}^{2} / \mathrm{ms}\right.$, or $\left.\mathrm{cm}^{2} / \mathrm{s}\right), S_{\mathrm{ij}}$ is the effective surface area contact between source and target patches $\left(\mu \mathrm{m}^{2}\right),\left[\mathrm{O}_{2}\right]_{\mathrm{i}}$ is the oxygen concentration of the source patch $(\mathrm{amol} / \mathrm{patch}$, or $\mu \mathrm{M})$, $\mathrm{q}^{\mathrm{i}} \mathrm{O}_{2}(\mathrm{t}+1), \mathrm{q}^{\mathrm{i}} \mathrm{O}_{2}(\mathrm{t})$ are the oxygen content of patch « $\mathrm{i}$ » (amol); $\mathrm{n}, \mathrm{e}, \mathrm{s}, \mathrm{w}$ refer to north, east, south and west neighboring patches, respectively.

\subsubsection{Equations for Oxygen Consumption}

Capillaries (PTC) and interstitium (INT): capillary specific consumption rate is extracted from literature: $1.2 \pm 1.1 \mathrm{mM} / \mathrm{min}$ (SM1-Table S5). PTC patches are considered consuming through their endothelial component $(0.5-1 \mu \mathrm{m}$ thick, not represented), scaled to the corresponding crown volume fraction.

$$
\begin{aligned}
& \mathrm{JHK}_{\text {cap }}=\left[0_{2}\right] \cdot \frac{\operatorname{Jmax}_{\text {cap }}}{\mathrm{Km}+\left[0_{2}\right]} \\
& \mathrm{qO}_{2}(\mathrm{t}+1)=\mathrm{qO}_{2}(\mathrm{t})-\mathrm{JHK}_{\text {cap }}
\end{aligned}
$$

with $\mathrm{JHK}_{\text {cap }}$ is the PTC house-keeping oxygen consumption: amol/patch/ms (patch unit, $\mathrm{PU}$ ), $\left[\mathrm{O}_{2}\right]$ is the patch oxygen concentration (amol/patch, or $\mu \mathrm{M}$ ), Jmax cap is the PTC maximal rate of oxygen consumption (PU; see SM1-Table S6), $\mathrm{Km}$ is the cytochrome C oxidase $\mathrm{Km}$ for $\mathrm{O}_{2}(\mu \mathrm{M}), \mathrm{qO}_{2}(\mathrm{t}+1)$, $\mathrm{qO}_{2}(\mathrm{t})$ are the patch oxygen content (amol).

RCM also considers oxygen consumption by interstitial cells (e.g., fibroblasts, resident macrophages). This is detailed in supplement SM2 (Section 2). Consumption equations are the same as for PTC. The $\mathrm{Km}\left(\mathrm{O}_{2}\right)$ value of house-keeping, non-transport-related consumption is set by default to the same value as Oxphos $(1.1 \mu \mathrm{M}$; see below). 
Epithelial patches: the $\mathrm{Km}\left(\mathrm{O}_{2}\right)$ value of the oxidative phosphorylation is $\mathrm{Km}$, $\mathrm{Cox}^{\circ}=1.1 \pm 1.0 \mu \mathrm{M}$ (SM1-Table S5).

$$
\begin{gathered}
\mathrm{JHK}_{\text {epi }}=\left[0_{2}\right] \quad \frac{\operatorname{Jmax}_{\text {epi }}}{\mathrm{Km}+\left[0_{2}\right]} \\
\mathrm{JTNa}=\frac{0.33}{\frac{P}{0_{2}}}\left[0_{2}\right] \quad . \quad \mathrm{TNa} \cdot \operatorname{frTC} \cdot \frac{\left[0_{2}\right]}{\mathrm{Km}+\left[0_{2}\right]} \\
\mathrm{qO}_{2}(\mathrm{t}+1)=\mathrm{qO}_{2}(\mathrm{t})-\mathrm{JHK}_{\text {epi }}-\mathrm{JTNa}
\end{gathered}
$$

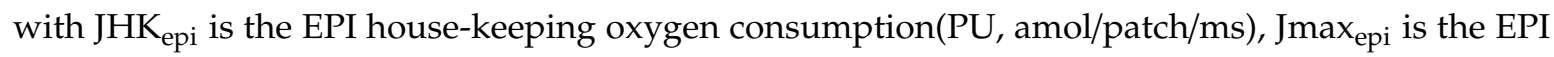
maximal rate of oxygen consumption (PU), JTNa is the transport-related oxygen consumption (PU), $\mathrm{P} / \mathrm{O}_{2}$ is the ATP $/ \mathrm{O}_{2}$ Oxphos stoichiometry $\left(2 \times\right.$ " $\mathrm{P} / \mathrm{O}^{\prime}$, see SM1-Table S5), 0.33 corresponds to the ATP $/ \mathrm{Na}^{+}$stoichiometry of the NaK-pump, TNa is the EPI sodium transport (PU), frTC is the fractional transcellular $\mathrm{Na}^{+}$transport.

\subsection{Modeling and Simulation}

The cortical tissue model is transversally perfused by blood (via capillary sections) and by post-glomerular filtrate (via tubule sections). Volumic flows (and TNa fluxes) are considered occurring, on the average, at mid-length of capillaries and tubules (see Equations (7) and (8)). In the present version of RCM, proximal convoluted tubule (PCT, roughly corresponding to S1 and S2) and pars recta (PR, S3) are not discriminated (parameters values taken from PCT references; see SM1-Table S3a,b); similarly, distal tubule sections are not represented (see Discussion). In NetLogo, one execution step is called a tick, during which equations and rules are executed, for all patch agents, and variables accordingly updated. Tick duration used in this study was $1 \mathrm{~ms}$ (see Results). Note however that control simulations (not shown) indicate that the current version of RCM is able to numerically tolerates durations up to 10-20 ms, depending on flow-related inputs and parameters (RBF and filtration fraction).

\subsection{Data Handling and Statistical Calculations}

Bibliographical and reference data are given as mean \pm SD of $\mathrm{n}$ determinations, from $\mathrm{N}$ sources; when missing, the number of determinations was conservatively set to 3 (Tables in SM1, Section 2).

In a mathematical model, inputs and independent parameters (IP) are formally equivalent. However, we performed parametric and I/O sensitivity analysis (SA) separately. Local SA (i.e., one parameter varied at a time) was performed, at steady-state for tissue $\mathrm{PO}_{2}\left(\mathrm{sstPO}_{2}\right)$, by varying the value of the tested IP around its $\mathrm{BV}^{\circ}$, within its range, $\pm \Delta \mathrm{p}$ (usually, $20 \%$ of $\mathrm{BV}^{\circ}$ ). The relative sensitivity coefficient, RSC, for parameter IP influence upon $\mathrm{sstPO}_{2}$, is calculated as:

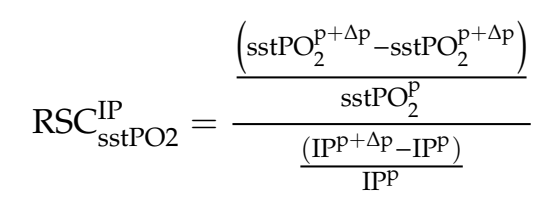

where sstPO $\mathrm{PO}_{2}$ refers to average, steady-state tissue $\mathrm{PO}_{2}$, $\mathrm{p}$ refers to reference value of the parameter being evaluated, $\Delta \mathrm{p}$ refers to the variation applied to the parameter, and IP, refers to the (independent) parameter tested.

By construction, the two main morphometric parameters, $\mathrm{Nc} / \mathrm{Nt}$ (capillary density) and tubule diameter, are cast within the tissue geometry. To perform SA with these parameters, appropriate model tissues were used (see tissue variants in SM2, Section 1). 


\section{Results}

\subsection{Bibliographical Analysis and Reference Values}

Biological values (BV) extracted from the bibliographical analysis categorize as: independent parameters $(\sim 33)$, dependent parameters $(\sim 64)$, three inputs $\left(\mathrm{RBF}, \mathrm{PTC}\right.$ and $\mathrm{LUM} \mathrm{PO}_{2}$ feeds) and one main output, steady-state tissue oxygen pressure. Table 1 lists the reference values for principal inputs and parameters $\left(\mathrm{BV}^{\circ}\right)$. The whole corpus, its analysis and the extracted values for parameters and variables are presented in the Supplementary Materials (SM1-Tables S1 to S8).

Table 1. Principal variables and parameters used in RCM (reference setting, $\mathrm{RCM}^{\circ}$ ).

\begin{tabular}{|c|c|c|c|c|}
\hline Name & Description & Value & Unit & SM1 Table \\
\hline $\mathrm{RBF}$ & Renal blood flow & 5.3 & $\mathrm{~mL} /(\mathrm{gkw} \cdot \mathrm{min})$ & Table S1 \\
\hline $\mathrm{PTC} \mathrm{PO}_{2}$ & Capillary $\mathrm{PO}_{2}$ & 56 & $\mathrm{mmHg}$ & Table S1 \\
\hline LUM $\mathrm{PO}_{2}$ & Luminal $\mathrm{PO}_{2}$ & 40 & $\mathrm{mmHg}$ & Table S1 \\
\hline FF & Filtration fraction & 0.34 & - & Table S2 \\
\hline $\mathrm{Nb}$ & Nephron number & 32,400 & - & Table S2 \\
\hline Rc & Capillary radius & 5.0 & $\mu \mathrm{m}$ & Table S3a \\
\hline Tub-length & Tubule length & 10,400 & $\mu \mathrm{m}$ & Table S3a \\
\hline Bbmf & EPI-LUM surface area & 2000 & $\mu \mathrm{m}^{2}$ & Table S3b \\
\hline ppsa & EPI-EPI surface area & 800 & $\mu \mathrm{m}^{2}$ & Table S3b \\
\hline pcsa & PTC-EPI surface area & 157 * & $\mu \mathrm{m}^{2}$ & Table S3b \\
\hline pcsint & PTC-INT surface area & $39 *$ & $\mu \mathrm{m}^{2}$ & estimated \\
\hline frReab & Fractional reabsorption & 0.51 & - & Table S4 \\
\hline frTransC & Na Transcell. fraction & 0.81 & - & Table S4 \\
\hline $\mathrm{P} / 0$ & Oxphos ATP $/ \mathrm{O}_{2}$ & 4.5 & - & Table S4 \\
\hline Km-Cox & $\mathrm{Km}$ for $\mathrm{O}_{2}$ consumption & 1.1 & $\mu \mathrm{mol} / \mathrm{L}$ & Table S4 \\
\hline Hta & Arterial Hematocrit & 0.45 & - & Table S6 \\
\hline Nap & Plasma $\mathrm{Na}^{+}$ & 142 & $\mathrm{mmol} / \mathrm{L}$ & Table S6 \\
\hline $\mathrm{Hb} 4-\mathrm{RBC}$ & $\mathrm{RBC} \mathrm{Hb}$ concentration & 5.2 & $\mathrm{mmol} / \mathrm{L} \cdot \mathrm{rbc}{ }^{* * *}$ & Table S6 \\
\hline $\mathrm{P}_{50}$ & $\mathrm{Hb}$ half-saturation $\mathrm{PO}_{2}$ & 36.8 & $\mathrm{mmHg}$ & Table S6 \\
\hline $\mathrm{DO}_{2}-\mathrm{PTC}$ & Diffusion constant & $1.40 \times 10^{-5}$ & $\mathrm{~cm}^{2} / \mathrm{s}$ & Table S7 \\
\hline $\mathrm{DO}_{2}$-LUM & Diffusion constant & $2.80 \times 10^{-5}$ & $\mathrm{~cm}^{2} / \mathrm{s}$ & Table S7 \\
\hline $\mathrm{DO}_{2}$-EPI & Diffusion constant & $1.10 \times 10^{-5}$ & $\mathrm{~cm}^{2} / \mathrm{s}$ & Table S7 \\
\hline $\mathrm{DO}_{2}$-INT & Diffusion constant & $2.20 \times 10^{-5}$ & $\mathrm{~cm}^{2} / \mathrm{s}$ & Table S7 \\
\hline alpha & $\mathrm{O}_{2}$ solubility & 1.34 & $\mu \mathrm{M} / \mathrm{mmHg}$ & Table S8 \\
\hline fBIC & $\mathrm{HCO}_{3}$-factor ** & 1.15 & - & - \\
\hline
\end{tabular}

*, at Rc = 5.0; nb: the PTC-EPI and PTC-INT exchange surface areas (ESA) have been adjusted to 2-fold and 0.5-fold (with respect to the $100 \mu^{2}$ reference ESA), respectively, to represent the fact that capillaries are dominantly in contact with tubules, not with the interstitium (see text). ${ }^{* *}$, the "bicarbonate factor" implements the fact that, in early sections of the convoluted proximal tubule (segments $\mathrm{S} 1$ and S2), the basolateral $\mathrm{Na}^{+}-3 \mathrm{HCO}_{3}{ }^{-}$cotransport system increase $\mathrm{Na}^{+}$reabsorption by up to $50 \%$, independently of the $\mathrm{Na}^{+}-\mathrm{K}^{+}$- pump, at no ATP or oxygen cost, $[14,22,46]$. ***, red blood cells.

$\mathrm{RCM}^{\circ}$ parametric setting corresponds to the model with its parameters (and inputs) all set at their reference value $\left(\mathrm{BV}^{\circ}\right)$; $\mathrm{nb}$ : an improved variation of this setting, noted $\mathrm{RCM}^{*}$, will be introduced later; see Section 3.4.

\subsection{Model Verification}

Internal consistency and code checking were regularly carried out.. In addition, we performed careful verification of morphological and functional aspects of RCM. For concision, we present below the verification of tissue perfusion and transport-related (epithelial) consumption processes. Details of other oxygen-related processes, i.e., the hemoglobin/oxygen equations, the patch-to-patch oxygen diffusion routine, and the non-epithelial consumption are given in Supplementary Materials (SM2). Similarly, comparative verification of the model tissue morphometry with regard to histological data from the rat renal cortex is also reported in SM2. 


\subsubsection{Verification of Tissue Perfusion}

Model perfusion, depends on a cascade of algebraic equations, from RBF down to capillary and tubular volumic flows (CVF and TVF, resp.; Equations (1)-(8)). We verified that the reference values $\left(\mathrm{BV}^{\circ}\right)$ of the independent (or external) parameters (e.g., filtration fraction) which drive the flows yield expected values $\left(\mathrm{BV}^{\circ}\right)$ of the flow-related dependent parameters (e.g., TVF).

Figure 2 plots the ratio of flow-driving parameters to their $\mathrm{BV}^{\circ}$ counterpart (all independent parameters set to $\mathrm{BV}^{\circ}$ ). Experimental $\mathrm{CVF}^{\circ}$ is rare, and scattered in the $10-30 \mathrm{~nL} / \mathrm{min}$ range [11]. For simplicity, we used $20 \mathrm{~nL} / \mathrm{min}$, the mean value, of the reported $\mathrm{BV}^{\circ}$ (SM1-Table S2). $\mathrm{RCM}^{\circ}$ flow-related values fall within $1 \mathrm{SD}$ of their $\mathrm{BV}^{\circ}$, except for tubular flow TVF, slightly overestimated. Including the retro-calculation of the whole-kidney glomerular filtration rate (GFR) (wk-GFR, right-most bar in Figure 2), the mean $\mathrm{RCM}^{\circ}$-simulated/BV ${ }^{\circ}$ ratio for flow-related processes is $0.99 \pm 0.22(n=$ 10, range $0.73-1.38$ ). This argues for a fair representation and distribution of flows, and accordingly, oxygen delivery in the model.

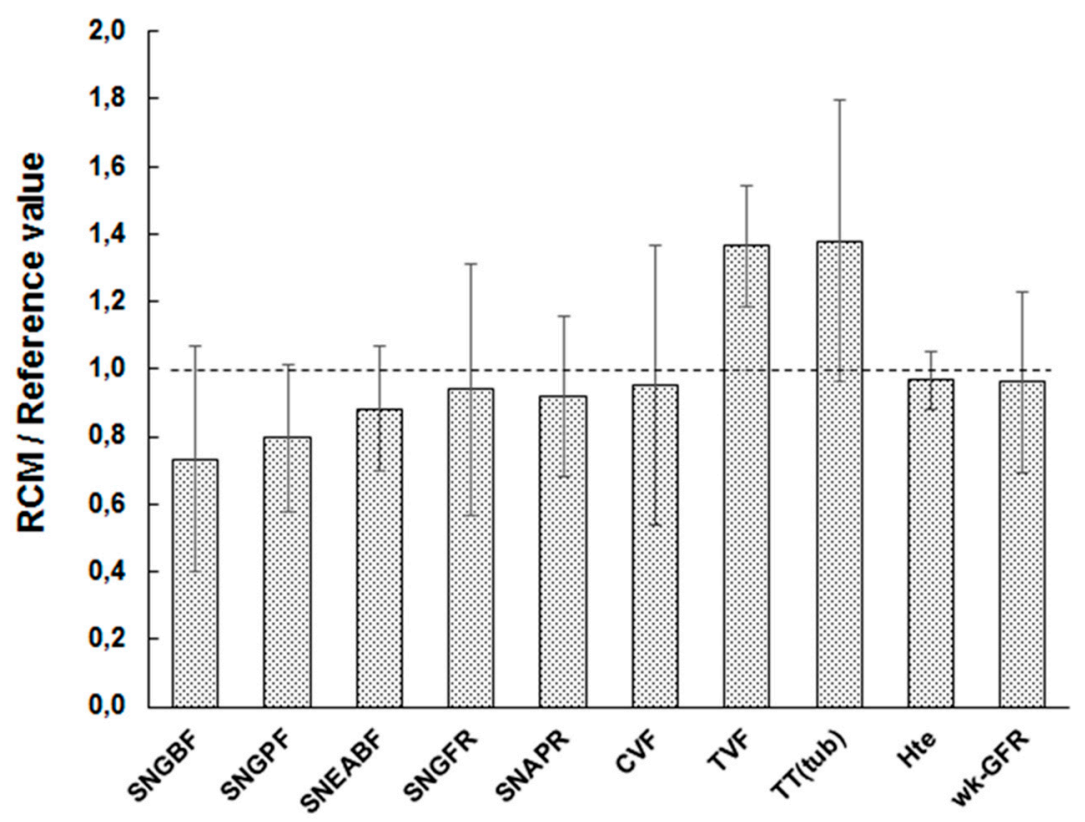

Figure 2. Verification of flow-related processes in the model. RCM is set under $\mathrm{RCM}^{\circ}$ settings (reference tissue "1540"), for inputs and for independent parameters, including flow-driving parameters (nephron number, hematocrit, filtration fraction, capillary branching factor, and tissue "1540" geometry—capillary number and tubule diameter). The nine left bars correspond to the ratio of model tissue over reference value for dependent parameters. All volumic flow-related values fall within 1 SD of their bibliographical, reference value $\left(\mathrm{BV}^{\circ}\right)$. The right-most column shows that whole kidney-equivalent glomerular filtration rate (GFR) is also accurately reproduced.

\subsubsection{Verification of Transport-Related Oxygen Consumption}

In EPI patches, the main oxygen consumers, the transport-related $\mathrm{QO}_{2}$ is dynamically calculated by converting reabsorptive sodium transport $(\mathrm{TNa}$, a linear function of filtered load and fractional reabsorption, Equation (10) into oxygen cost, using the $\mathrm{Na}^{+} / \mathrm{K}^{+}$-pump Na/ATP and ATP $/ \mathrm{O}_{2}$ Oxphos stoichiometric ratio (SM1-Table S4). On the other hand, the non-respiratory, house-keeping consumption (HK-QO ${ }_{2}$-EPI) had to be estimated from a detailed partitioning of kidney consumption. This lengthy accounting exercise, based on renal basal consumption [15], fractional cortical volume and several other parameters, is presented in Supplementary Materials (SM2). Calculations yield a reference $\mathrm{HK}-\mathrm{QO}_{2}$-EPI of $1.9 \pm 0.8 \mathrm{mM}$-EPI/min. Ignoring non-epithelial $\mathrm{QO}_{2}\left(<5 \%\right.$ of total consumption), $\mathrm{RCM}^{\circ}$ exhibits an oxygen consumption of about to $\sim 7.7 \mathrm{mM}$-ctx $/ \mathrm{min}$, i.e., 1.18 fold the expected renal cortical 
consumption $(6.5 \pm 1.3 \mathrm{mM}$-ctx/min, SM2-Table S3). This suggests a proper assignment of oxygen consumption in the model.

A second, independent, line of verification is provided by the $\mathrm{Na}^{+} / \mathrm{K}^{+}$-pump activity-the ultimate driver of trans-epithelial $\mathrm{Na}^{+}$reabsorption. In proximal cells, specific maximal pump activity is $396 \pm 320 \mathrm{mM}-\mathrm{EPI} / \mathrm{min}$ (SM1-Table S4). Using the pump and Oxphos stoichiometry $\left(3 \mathrm{Na}^{+} / \mathrm{ATP}^{\text {[42], }}\right.$ and 4.6 ATP/O $/ \mathrm{O}_{2}$, resp.; see SM1-Table S4), this converts into a $\mathrm{QO}_{2}$ equivalent of $26.4 \mathrm{mM}-\mathrm{EPI} / \mathrm{min}$; on the other hand, $\mathrm{RCM}^{\circ}$ simulated $\mathrm{TNa}-\mathrm{QO}_{2}$ amounts to $10.2 \mathrm{mM}-\mathrm{EPI} / \mathrm{min}$, well below the above maximum. Since no explicit pump is present in RCM, these calculations indicate that TNa-related $\mathrm{QO}_{2}$ realistically complies with rat proximal transport capacity.

Based on the above arguments, we considered RCM to be satisfactorily verified and consistent. Nevertheless, at this point, we must point at two perfusion and oxygen-related features which remain unsatisfactorily simulated. First, the transport efficiency ratio $\left(\mathrm{TNa} / \mathrm{QO}_{2}\right)$ simulated by $\mathrm{RCM}^{\circ}$ was $\sim 11.3$, below the reported range (15-26, mean value $=19$; [15]). Second, $\mathrm{RCM}^{\circ}$ apparent capillary "blood velocity", was $\sim 5 \mathrm{~mm} / \mathrm{s}$, somewhat outside the range of $\mathrm{BV}^{\circ}(0.5-4.1 \mathrm{~mm} / \mathrm{s}$; mean $1.1 \mathrm{~mm} / \mathrm{s}$, SM1-Table S1). Addressed below (Section 3.4), both issues relate to more complex cell and tissue features, that absent from the presented model, namely energetic metabolism and capillary hemodynamics.

\subsection{Parametric Sensitivity Analysis and I/O Analysis}

In order to characterize model dependence versus parameters and input/output values, we performed parametric sensitivity analysis (SA), input/output analysis (I/O), and input-parameter interaction analysis. Detailed parametric sensitivity analysis is given in SM1, together with input-parameter interactions. Here below, we consider parametric influence upon model output (derived from SA), and the $\mathrm{I} / \mathrm{O}$ analysis. With respect to model output $\left(\mathrm{tPO}_{2}\right.$, tissue $\left.\mathrm{PO}_{2}\right)$, parametric SA allows to compare the relative influence of all parameters with each other, independently of their own numerical scale (see SM1). Second, it allows us to evaluate the influence of each parameter upon model output, given their own experimental uncertainty (SM1-Tables S1-S8). Table 2 reports the 12 most influent parameters (absolute value of associated error $>0.5 \mathrm{mmHg}$ ); signs indicate the direction of parameter influence. For instance, experimental SD uncertainty about the transcellular $\mathrm{Na}^{+}$ reabsorption fraction $(0.81 \pm 0.20$, range $0.53-1.00$; SM1-Table S4, energetics and transport) translates into a tissue $\mathrm{PO}_{2}$ error of $2.3 \mathrm{mmHg}$.

Table 2. Influence of main parameters on tissue $\mathrm{PO}_{2}$ output.

\begin{tabular}{lcc}
\hline Parameter & Description & Parameter-Dependent Error (mmHg) \\
\hline frReab & Fractional reabsorption & $3.1(-)$ \\
HKQO2EPImax & Maximal rate of basal $\mathrm{QO}_{2}{ }^{*}$ in EPI & $3.0(-)$ \\
frTransC & Transcellular Na reabsorption fraction & $2.3(-)$ \\
bbmf & Brush-border membrane factor & $0.7(+)$ \\
fPCSA & Surface area factor for PTC & $1.0(+)$ \\
DO2-EPI & Diffusion coefficient in EPI & $1.0(+)$ \\
ATP-O2 & Oxphos ATP/O ratio $^{-}$ & $1.4(+)$ \\
fBIC & $\mathrm{HCO}_{3}^{-}$factor & $1.4(+)$ \\
alpha & Tissue oxygen solubility & $1.7(+)$ \\
Nc/Nt & Capillary/Tubule ratio & $1.9(+)$ \\
Rcap & Capillary radius & $2.5(+)$ \\
Tub-length & Tubule length & $2.9(+)$ \\
\hline
\end{tabular}

${ }^{*}, \mathrm{QO}_{2}$, oxygen consumption.

\subsubsection{Parametric Sensitivity Analysis}

Averaging the absolute value of errors for all 22 parameters, we obtain an estimation for (parameter-dependent) model accuracy of $1.1 \pm 1.1 \mathrm{mmHg}$ (range 0.0-3.1). Since experimental SD has 
no sign by definition, we conservatively consider RCM error as twice this value, $2.2 \mathrm{mmHg}$. Within $\mathrm{RCM}$, the standard-deviation of $\mathrm{PO}_{2}$ patches is $4-5 \mathrm{mmHg}$.

\subsubsection{Input/Output Analysis}

RCM features three main inputs, $\mathrm{RBF}$ and feeding $\mathrm{PO}_{2}$ via $\mathrm{LUM}$ and/or PTC patches. The following analysis was carried with all parameters set at $\mathrm{BV}^{\circ}$. Figure 3 presents model response in term of tissue $\mathrm{PO} 2$ (sstPO $\mathrm{P}_{2}$ ), as a function of RBF, at two combinations of feeding $\mathrm{PO}_{2}$ from PTC (capillaries) and $\mathrm{LUM}$ (tubules). In the reference condition (open circles, $\mathrm{PTC} / \mathrm{LUM}=56 / 40$ ), the $\mathrm{sstPO}_{2}$ is practically insensitive to RBF (slope $\sim 0.0 \mathrm{mmHg} / \mathrm{FU}$ ) in the 3.0-10.0 mL/(min.gkw) (or "flow units", FU), around $\mathrm{BV}^{\circ}$ (5.3 FU). Conversely, when RBF decreases below $3 \mathrm{FU}$, its control over model $\mathrm{PO}_{2}$ progressively increases: around $2.0 \mathrm{FU}$, the control slope increases to $2.5 \mathrm{mmHg} / \mathrm{FU}$, while it sharply increases below $1.0 \mathrm{FU}$, to $\sim 15-50 \mathrm{mmHg} / \mathrm{FU}$. Using lower $\mathrm{PO}_{2}$ inputs (PTC/LUM $=28 / 20$, grey circles), the model $\mathrm{PO}_{2}$ response to RBF is qualitatively similar, exhibiting insensitivity to RBF in the 3-10 FU range and marked increase below $2.0 \mathrm{FU}$; however, in the latter ischemic range, $\mathrm{RBF}$ control over $\mathrm{sst} \mathrm{PO}_{2}$ is more modest, in the $5-8 \mathrm{mmHg} / \mathrm{FU}$ range.

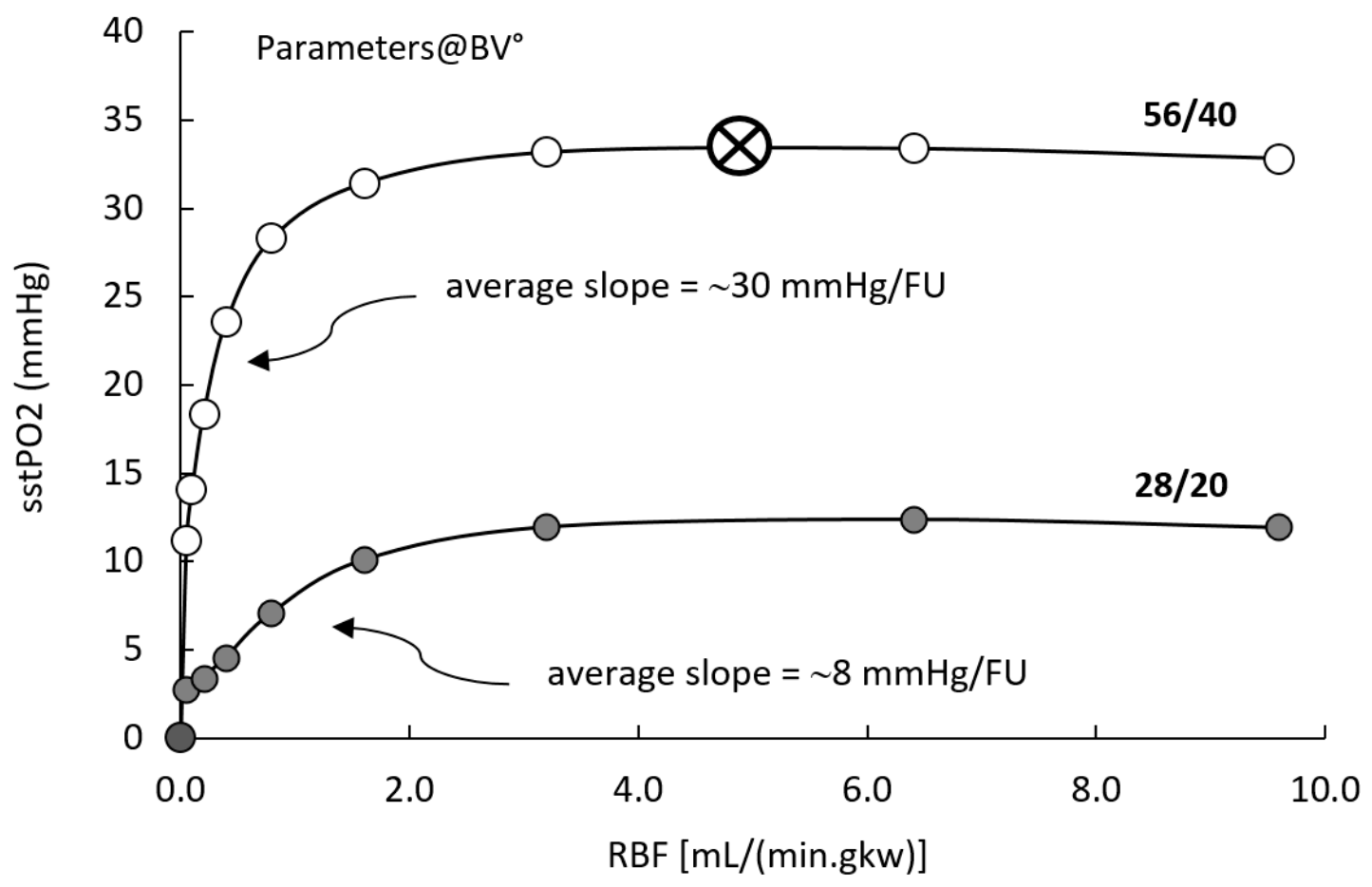

Figure 3. Input/output analysis. Tissue $\mathrm{PO}_{2}$ (output) as a function of RBF, and PTC and LUM PO2 (inputs). $\mathrm{RCM}^{\circ}$ parametric configuration. $\mathrm{RBF}$ is varied from zero to $10 \mathrm{~mL} /(\mathrm{min} . \mathrm{gkw})$ (flow unit, $\mathrm{FU}$ ), while capillary and luminal $\mathrm{PO}_{2}$ inputs are set either to reference conditions (PTC/LUM = 56/40, open circles)or to reduced oxygen feed (PTC/LUM = 28/20, grey circles). The open circle/cross symbol indicates the $\mathrm{RBF}$ and $\mathrm{PO}_{2}$ feed reference conditions.

We then considered model output as a function of $\mathrm{PO}_{2}$ inputs. Figure 4 (upper panel) shows model output (sstPO $\mathrm{P}_{2}$ ) response as a function of $\mathrm{PTC} \mathrm{PO}_{2}$ input, panel A (resp. LUM, panel B), at three levels of RBF perfusion, while $\mathrm{LUM} \mathrm{PO}_{2}$ input (resp. PTC) is kept fixed at its reference value. For each level of RBF, we determine the slope of the output dependence versus the input (nb: calculation performed around the reference value, 56 and $40 \mathrm{mmHg}$ for PTC and LUM, resp.). Panel C plots the output/input slope dependence as a function of RBF. It can be seen that under reference perfusion $\left(\mathrm{RBF}^{\circ}\right)$ the influence of PTC input on $\mathrm{RCM} \mathrm{PO}_{2}$ is $0.17 \mathrm{mmHg} / \mathrm{mmHg}$ while for LUM it is $0.72 \mathrm{mmHg} / \mathrm{mmHg}$; when RBF is reduced, the control exerted by PTC and LUM inputs respectively increases and decreases and the relative influences of $\mathrm{PO}_{2}$ inputs is inverted. 

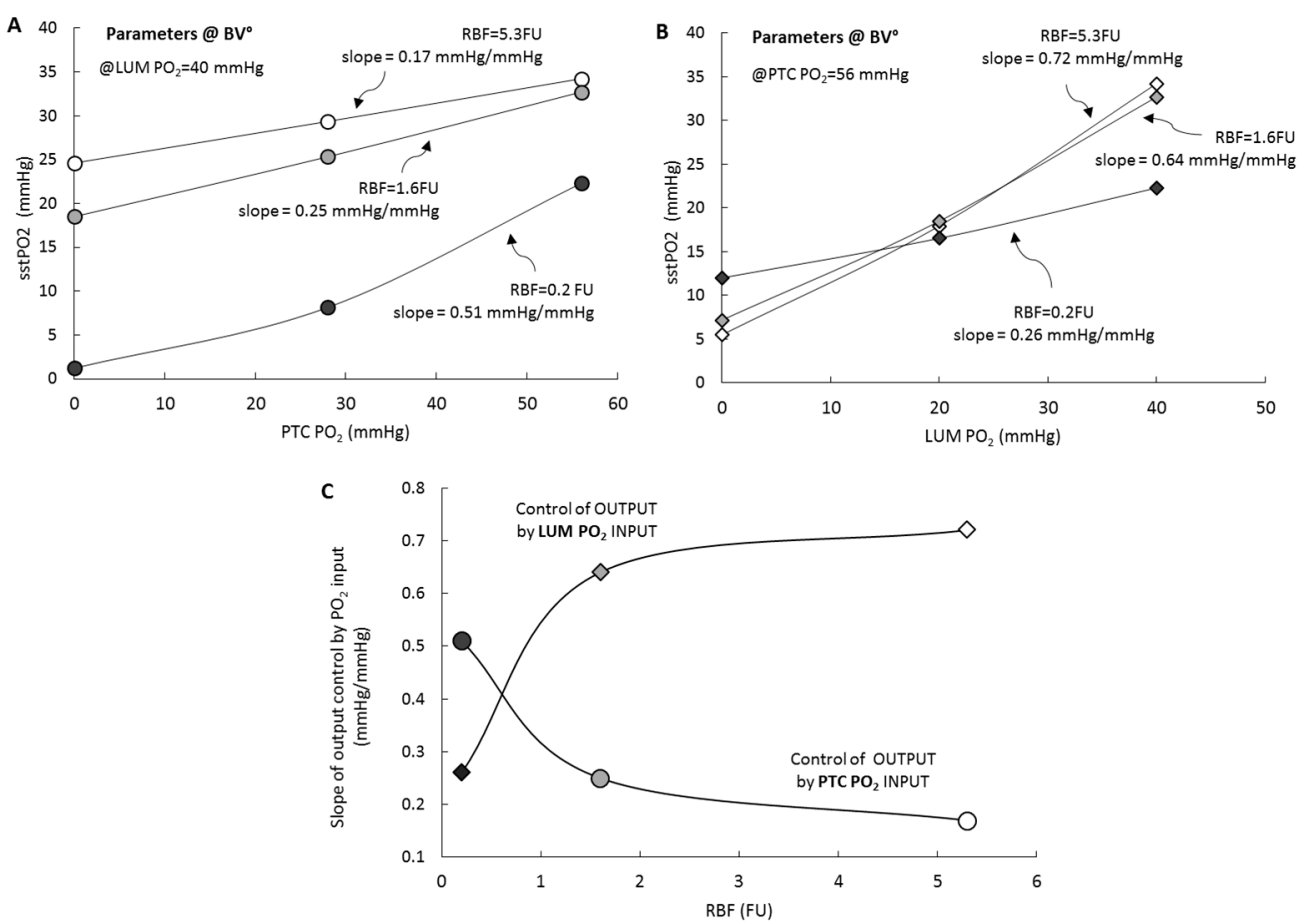

Figure 4. Input/output analysis. Tissue PO2 (output) is plotted as a function of PTC and LUM PO2 (inputs), at three levels of $\operatorname{RBF}\left(5.3,1.6\right.$ and $0.2 \mathrm{FU}$, respectively white, grey and black symbols). $\mathrm{RCM}^{\circ}$ parametric configuration. (A) (circles), PTC input is RBF is varied, while luminal PO2 input is kept constant (at its reference value, $40 \mathrm{mmHg}$ ). (B) (diamonds), LUM input is RBF is varied, while PTC PO2 input is kept constant (at its reference value, $56 \mathrm{mmHg}$ ). (C) Summarizes the results by plotting the output/input slopes for PTC (circles) and LUM (diamonds); symbols are color-coded as in A and B.

\subsubsection{Interactions of Inputs with Independent Parameters}

Because of the number of parameters, this analysis is given and detailed in Supplementary Materials (SM1). In summary, parameter control over model $\mathrm{PO}_{2}$ is not overall modified with oxygen inputs, (see SM1 and SM1-Figure S2). Thus, we also infer from this analysis that model "error" will not change significantly when modifying its oxygen feeding or perfusion inputs.

\subsubsection{Patch-Type Based Analysis}

Based on the patch-mapping of the renal cortex in RCM tissue, the model allows to monitor the oxygen level of its "histological" individual components. When simulating RCM under reference conditions $\left(\mathrm{RCM}^{\circ}\right)$, from initial state (all patches set to zero) up to steady-state, we observed that (Figure 5):

(i) the average $\mathrm{PO}_{2}$ of PTC's (white circles) adjusts almost exactly to PTC feed (Hb saturation at $75 \%$ ), within $0.5-1.0 \mathrm{mmHg}$, in $\sim 5 \mathrm{~ms}$;

(ii) $\mathrm{PO}_{2}$ in LUM patches (grey circles) settles to $35 \mathrm{mmHg}$, some $5 \mathrm{mmHg}$ lower than their $\mathrm{PO}_{2}$ feed, in about $350 \mathrm{~ms}$ (half-time $20 \mathrm{~ms}$ ), indicating that LUM patches deliver oxygen to the tissue;

(iii) EPI patches (grey squares) reach a steady-state level, $31 \mathrm{mmHg}$, in 250 ms (half-time $35 \mathrm{~ms}$ );

(iv) INT patches (dark diamonds), characterized by a low consumption, progressively fill up with oxygen, up to $\sim 32 \mathrm{mmHg}$, with a delay of $\sim 100 \mathrm{~ms}$ with regard to EPI patches (half-time $110 \mathrm{~ms}$ ); after $500 \mathrm{~ms}$, the interstitial compartment stabilizes at $32 \mathrm{mmHg}, \sim 1 \mathrm{mmHg}$ higher than EPI patches. 


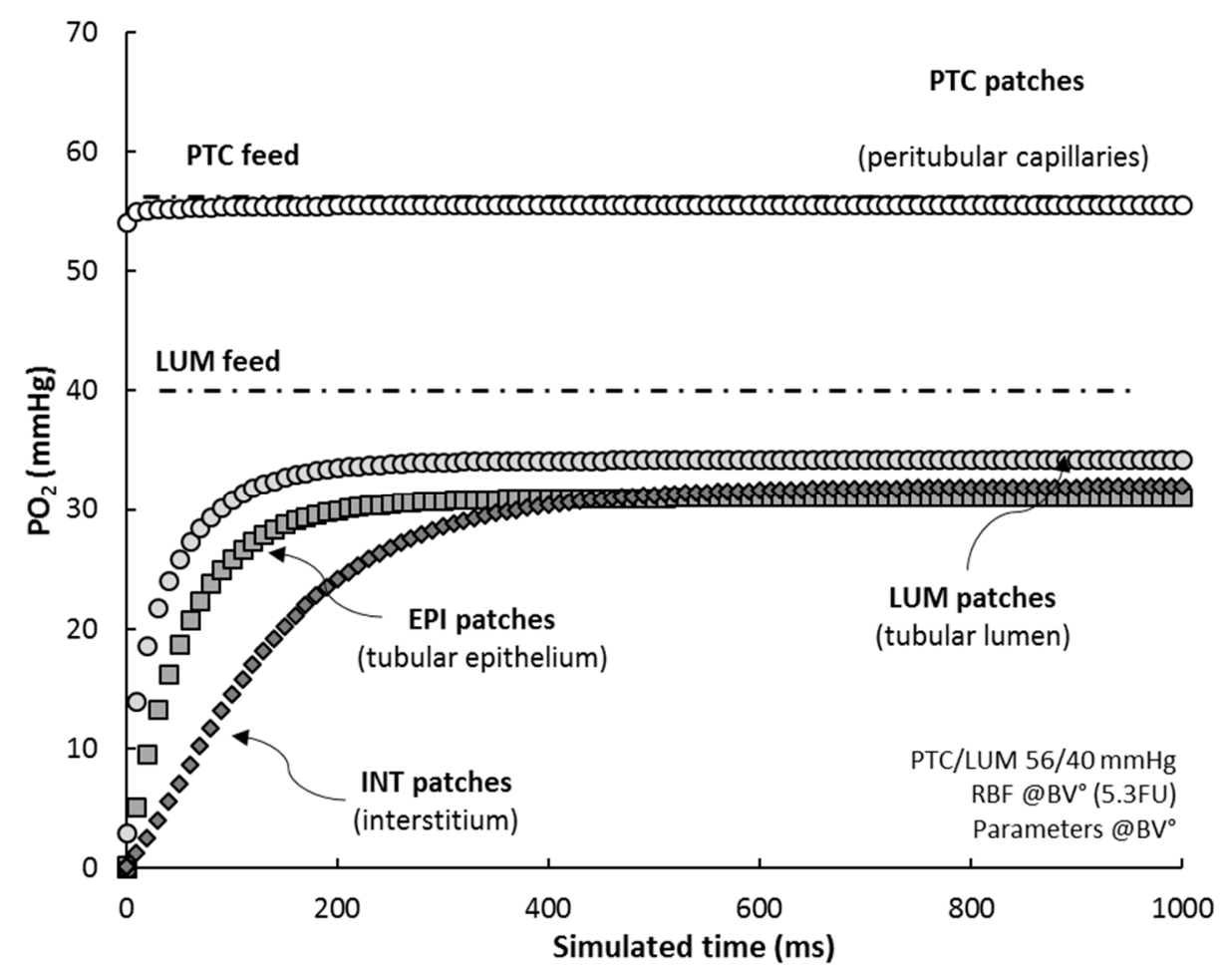

Figure 5. RCM "histological" compartments. Average $\mathrm{PO}_{2}$ for each patch-type compartment is shown. All patches were initialized at zero $\mathrm{PO}_{2}$ and $\mathrm{RCM}$ was simulated until steady-state $\left(\mathrm{RCM}^{\circ}, \mathrm{RBF}=5.3 \mathrm{FU}\right.$ and PTC/LUM feed = 56/40 mmHg; sampling time $10 \mathrm{~ms}$ ). For comparison, PTC and LUM feeds are also plotted (point-dotted lines).

\subsubsection{Influence of Hemoglobin}

In the parametric sensitivity analysis (see above), we observed, that, under normal conditions, hemoglobin-related parameters exhibit limited control over tissue $\mathrm{PO}_{2}\left(\mathrm{P}_{50}\right.$ and "blood" $\mathrm{Hb}$ concentration; see SM1 for details). In RCM, hemoglobin function is coded so as to allow the de-activation of its equations. Under normal conditions $\left(\mathrm{RCM}^{\circ}\right)$, when the model is run in the absence of hemoglobin, sstPO $\mathrm{PO}_{2}$ output is reduced by $\sim 0.1-0.2 \mathrm{mmHg}$, a surprisingly low value, well within model error.

We further analyzed this observation by evaluating the influence of $\mathrm{Hb}$ on tissue $\mathrm{PO}_{2}$, as a function of the $\mathrm{RBF}$ input and $\mathrm{PO}_{2}$ inputs.

Figure 6 shows that the influence of $\mathrm{Hb}$ on sstPO $\mathrm{PO}_{2}$ increases when it is decreased, reaching 6 and $15 \mathrm{mmHg}$ at RBF 0.5 and $0.2 \mathrm{FU}$, respectively (open circles).

Further exploring this effect, we observed that when LUM convection is de-activated (grey triangles), $\mathrm{Hb}$ contribution to tissue $\mathrm{PO}_{2}$ it is potentiated between in the 0.5 to $5.0 \mathrm{FU}$ RBF range (1-4 mmHg)). Overall, $\mathrm{Hb}$ control of $\mathrm{sstPO}_{2}$ is in the relatively low, e.g., $12 \mathrm{mmHg}$ under severely decreased $0.2 \mathrm{FU}$ ). The influence of both $\mathrm{PO}_{2}$ inputs on $\mathrm{Hb}$ contribution to tissue $\mathrm{PO}_{2}$ was also evaluated. We observed the low RBF-dependent control of $\mathrm{Hb}$ contribution depends mostly on PTC feed $(\triangle \mathrm{Hb} \sim 10 \mathrm{mmHg})$, versus LUM feed $(\Delta \mathrm{Hb} 2-3 \mathrm{mmHg}$; data not shown). Thus, when significant (under low RBF input), $\mathrm{Hb}$ control depends primarily on PTC feed. Accordingly, it vanishes when $\mathrm{Hb}$ is de-activated. Finally, under transient conditions, $\mathrm{Hb}$ alters noticeably RCM dynamic response. Setting RBF to zero from pre-established $\mathrm{RCM}^{\circ}$ tissue steady-state, if $\mathrm{Hb}$ is deactivated, the ischemic relaxation time to complete tissue anoxia $\left(\mathrm{tPO}_{2}<1 \mathrm{mmHg}\right)$ decreases two-fold by comparison to $\mathrm{RCM}$ with active $\mathrm{Hb}$ (from $\sim 600$ to $300 \mathrm{~ms}$ ). Hypoxemic relaxation time is $\sim 210 \mathrm{~ms}$ with $\mathrm{Hb}$, vs. $\sim 160 \mathrm{~ms}$ without $\mathrm{Hb}$. 


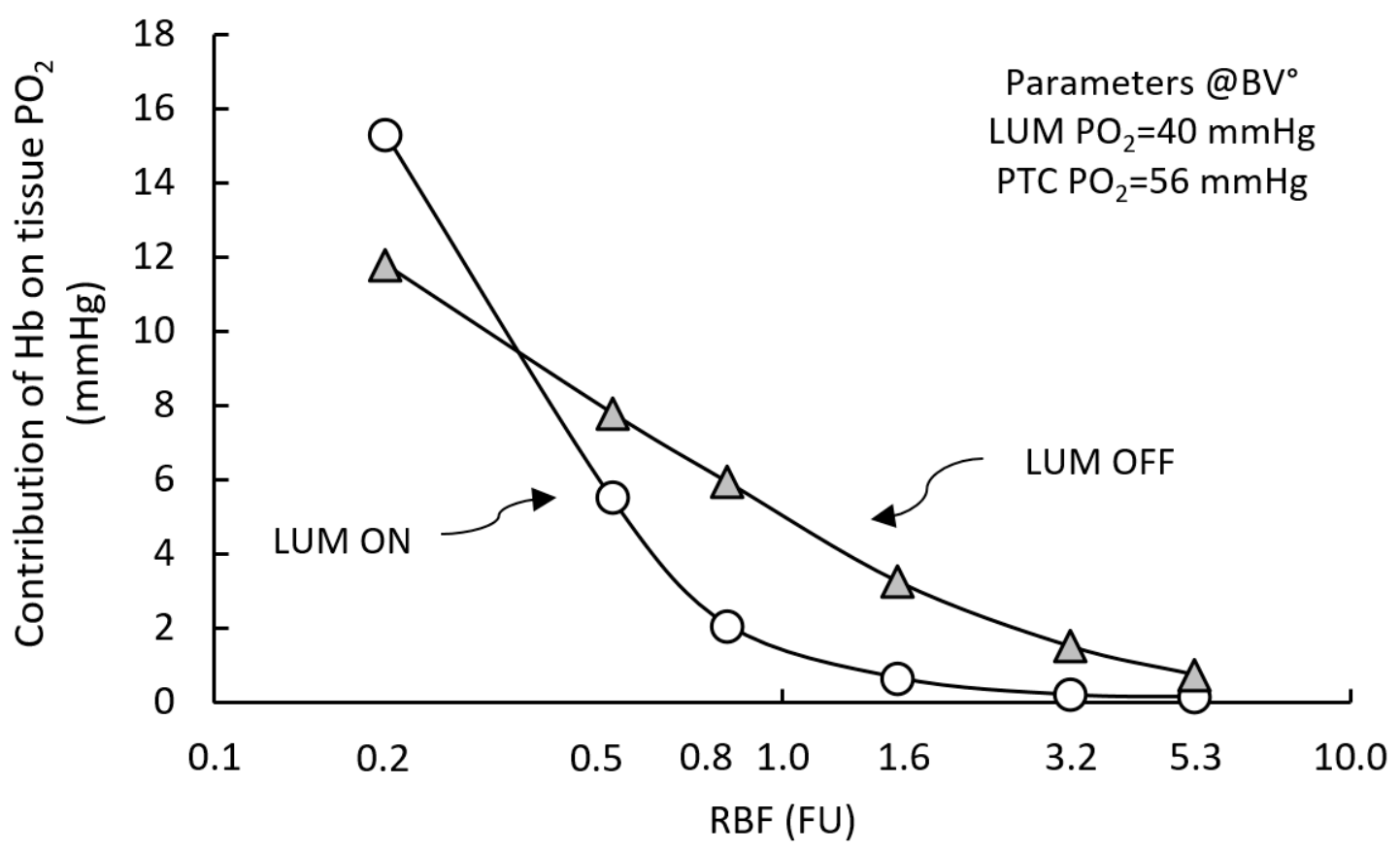

Figure 6. Contribution of hemoglobin on tissue $\mathrm{PO}_{2}$ as a function of $\mathrm{RBF}$ input. $\mathrm{RCM} \mathrm{M}^{\circ}$ parametric configuration. Hemoglobin $(\mathrm{Hb})$ contribution to tissue $\operatorname{sstPO}_{2}(\Delta \mathrm{Hb})$ is plotted as a function of RBF (open circles). $\Delta \mathrm{Hb}$ is negligible close to normal $\mathrm{RBF}(<1 \mathrm{mmHg}$, within model error), but it increases markedly with decreasing RBF, up to $\sim 15 \mathrm{mmHg}$ at $0.2 \mathrm{FU}$. Deactivating luminal convection shifts the curve rightwards, "unmasking" a substantial control of $\mathrm{Hb}$ over tissue $\mathrm{PO}_{2}(\sim 1-10 \mathrm{mmHg}$, grey triangles).

\subsection{Physiological Adjustments and Fine-tuning}

\subsubsection{Tubule and Reabsorption-Related Adjustments}

When independent parameters and inputs are set to their reference values $\left(\mathrm{RCM}^{\circ}\right)$, model $\mathrm{PO}_{2}$ $(\mathrm{sstPO})$ is $33.5 \pm 2.2 \mathrm{mmHg}$, within the experimental, reference determinations of tissue $\mathrm{PO}_{2}$ in the outer $\left(\mathrm{ocPO}_{2}{ }^{\circ}\right.$ ) and inner $\left(\mathrm{icPO}_{2}{ }^{\circ}\right)$ cortex, $40.8 \pm 6.2 \mathrm{mmHg}$ and $29.8 \pm 1.3 \mathrm{mmHg}$, respectively (see SM1-Table S1). Using 0.66 and 0.33 fractional volumes for the "outer" (superficial and mid-cortical nephrons), and inner (juxta-medullary nephrons), respectively, yields a cortical weighted average of $36.9 \pm 4.6 \mathrm{mmHg}$. Since $\mathrm{BV}^{\circ}$ relates to an "average" cortex, this represents preliminary evidence for RCM validity. There are, however, issues that need to be considered for model validation, all of them relating to $\mathrm{Na}^{+}$reabsorption and oxygen consumption. First, our bibliographical analysis is by definition based upon experimental determinations-with their own limitations, and some parameters require appropriate tuning. Second, the proximal tubule (PT), and especially its convoluted part (PCT, 2/3rd of PT), has the ability to drive $\mathrm{Na}^{+}$reabsorption via a basolateral $\mathrm{Na}^{+}-\mathrm{HCO}_{3}{ }^{-}$cotransport, independently of the $\mathrm{Na}^{+}-\mathrm{K}^{+}$-pump, and without costing ATP or oxygen [22,46].

The $\mathrm{BV}^{\circ}$ for fractional reabsorption is based on experimentally accessible parts of the proximal tubule (PT), neglects the distal tubule (DT, $2.0 \mathrm{~mm}, 9 \%$ reabsorption), and ignores reabsorption by the medulla (25\%; see SM2). Accordingly, we correct $\mathrm{RCM}^{\circ}$ settings by: (i) adjusting effective tubule length from 10.4 to $12.4 \mathrm{~mm}$ and fractional reabsorption from 0.51 to 0.75 . The $\mathrm{BV}^{\circ}$ value of transcellular reabsorption fraction $\left(\right.$ frCTNa $\left.{ }^{\circ}=0.81\right)$ translates into $\sim 18.0 \mathrm{TNa} / \mathrm{QO}_{2}$ ratio, whereas the experimental one, for the cortex (27.0, SM1-Table S4) converts into a 0.41-0.63 transcellular fraction (mean 0.56; [30,31,47]; SM1-Table S4). Adjusting frCTNa from 0.81 to 0.56 , the bicarbonate factor (fBic) from 1.15 to 1.5 , and increasing the ATP/O $\mathrm{O}_{2}$ ratio from 4.5 to 5.5 , yielded tissue $\mathrm{PO}_{2}$ to $35.9 \mathrm{mmHg}$ $\left(\mathrm{TNa} / \mathrm{QO}_{2} \sim 19\right)$. Table 3 summarizes the adjusted $\mathrm{RCM}$ setting $\left(\mathrm{RCM}^{*}\right)$, with respect to reference setting, $\mathrm{RCM}^{\circ}$. 
Table 3. Adjusted parameters used in $\mathrm{RCM}^{*}$ vs. $\mathrm{RCM}^{\circ}$.

\begin{tabular}{cccc}
\hline Name & Description & RCM $^{\circ}$ & RCM $^{*}$ \\
\hline Tub-length $(\mu \mathrm{m})$ & Total tubule length & 10,400 & 12,400 \\
frReab & Total fractional reabsorption & 0.51 & 0.75 \\
frTransC & Na Transcellular reabsorption fraction & 0.81 & 0.56 \\
fBIC & Bicarbonate-factor & 1.15 & 1.5 \\
$\mathrm{P} / 0$ & Oxphos ATP/O & \\
& Model output $\mathbf{P O}_{\mathbf{2}}(\mathbf{m m H g})$ & 4.5 & 5.5 \\
& & $\mathbf{3 4 . 2}$ & $\mathbf{3 5 . 9}$ \\
\hline
\end{tabular}

$\mathrm{RCM}^{\circ}$ and $\mathrm{RCM}^{*}$ respectively refer to the reference and the physiologically-adjusted parametric configurations (see text).

\subsubsection{Capillary Flow and Hemodynamics}

An important issue requires attention, relating to capillary microcirculation. In RCM, capillary flow is a simple distribution of post-glomerular flow down to capillaries, according to the capillary branching factor (Equation (7); [44]). This yields an apparent capillary "blood fluid" velocity of $5 \mathrm{~mm} / \mathrm{s}$ (at $\mathrm{RBF}^{\circ} 5.3 \mathrm{FU}$ ), an obvious overestimation versus the experimentally reported value (BV ${ }^{\circ}$ $1.1 \pm 1.3 \mathrm{~mm} / \mathrm{s}$; SM1-Table S2). The corresponding capillary residence time of oxygen $(\sim 2 \mathrm{~ms})$ might have been limiting its diffusion toward the nearby epithelial patches (EPI)—a possible explanation for the weak control exerted by hemoglobin on tissue $\mathrm{PO}_{2}$. We tested this hypothesis by applying a 0.25 "capillary factor" to PTC flow, thus increasing oxygen residence time 4-fold, to $8 \mathrm{~ms}$. The apparent capillary velocity was reduced to $1.2 \mathrm{~mm} / \mathrm{s}$ (within $\mathrm{BV}^{\circ}$ range): this increased $\mathrm{Hb}$ control over tissue $\mathrm{PO}_{2}$ t0.7 mmHg (vs. $0.1 \mathrm{mmHg}$ ). Setting the capillary test-factor to 0.1 (velocity $0.5 \mathrm{~mm} / \mathrm{s}, \sim 20 \mathrm{~ms}$ residence time), further increased hemoglobin contribution to tissue $\mathrm{PO}_{2}(\Delta \mathrm{Hb})$ to $1.5 \mathrm{mmHg}$, still lower than model accuracy. This issue will be thoroughly addressed in the Discussion, by comparison to well-studied, non-renal tissues. Because of the multi-parametric/input combinatorial, no further attempt was made to "optimize" RCM. A new model setting was defined and referred to as RCM* (see Table 3).

\subsection{Model Validation}

\subsubsection{Steady-State Condition}

Figure 7 compares five $\mathrm{RCM}^{*}$ model output sets (corresponding to various input combinations, all within experimental scatter) to seven experimental references, all based on direct tissue $\mathrm{PO}_{2}$ measurements in rat renal cortical tissue using micro-electrodes. The thin point-dotted lines correspond to the $\mathrm{BV}^{\circ}$ for the outer cortex and inner cortex $(40.8$ and $29.8 \mathrm{mmHg}$; see SM1-Table S1); the thick dotted line (36.9 $\mathrm{mmHg}$ ) represents the cortical average (see above). 


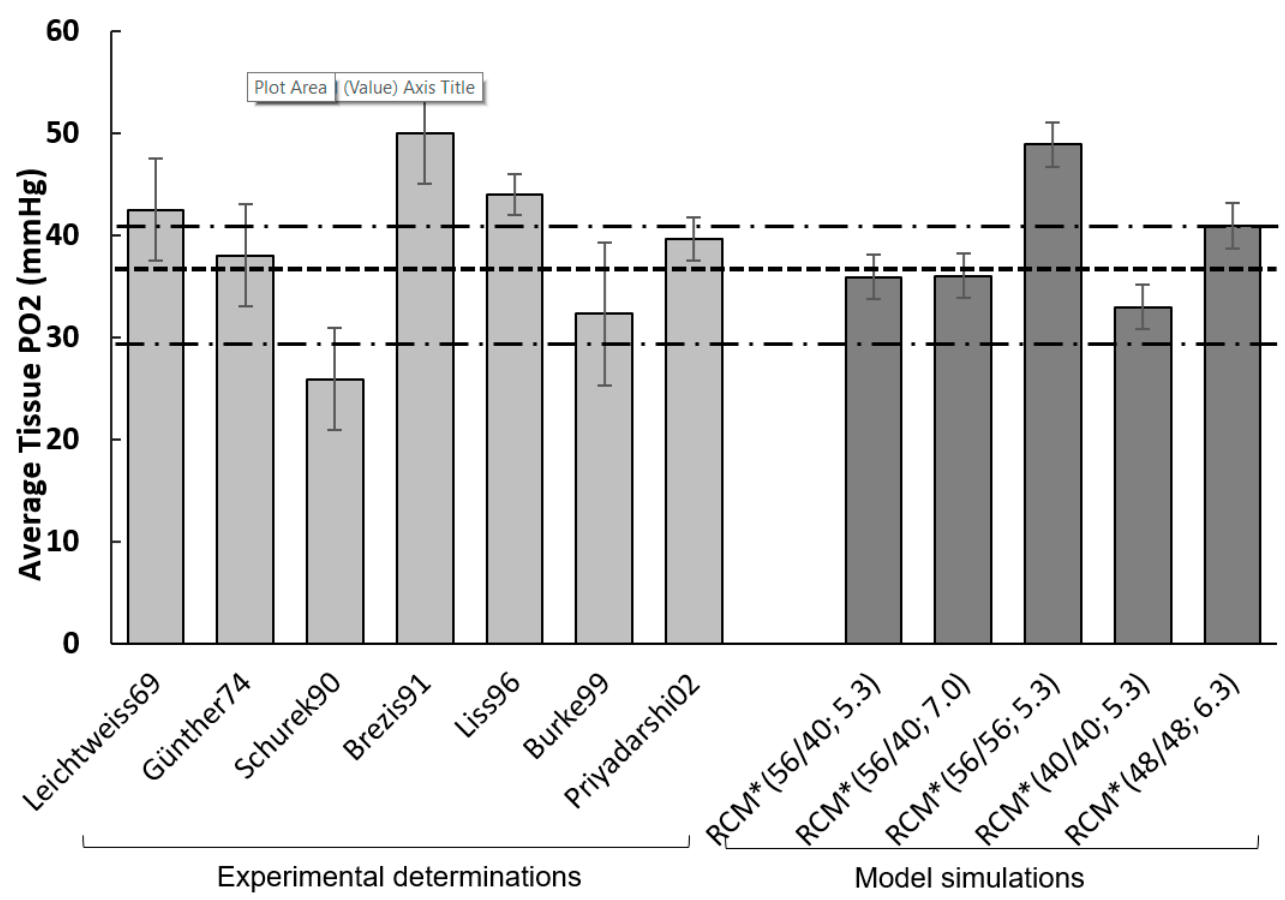

Figure 7. Validation under steady-state conditions. RCM simulations (dark grey) are compared to experimental references (light grey), all based on tissue $\mathrm{PO}_{2}$ measurements in rat renal cortical tissue using micro-electrodes (thus providing an average measure of tissue $\mathrm{PO}_{2}$; please recall that reported experimental values for the cortex range $\sim 20$ to $75 \mathrm{mmHg}$ ). Thin point-dotted lines correspond to the $\mathrm{BV}^{\circ}$ for the outer cortex and inner cortex; the thick line $(36.9 \mathrm{mmHg})$ represents the weighted cortical average ( $0.66 v / v$ outer cortex, $0.33 v / v$ inner cortex). RCM simulations were run under RCM* adjusted parametric setting (see text), with a panel of selected inputs combinations. Except for the 56/56 feed, $\mathrm{RCM} \mathrm{PO}_{2}$ falls within the SD range (see SM1-Table S1). Leichtweiss69 [11]; Schurek90 [48]; Burke99 [20]; Brezis91, cited in [13]; Günther74 PMID: 4603896; Liss96 PMID: 8731090; Priyadarshi02 PMID: 11849394.

$\operatorname{RCM}^{*}(56 / 40 ; 5.3)$ produces a tissue $\mathrm{PO}_{2}$ of $35.9 \mathrm{mmHg} . \mathrm{RCM}^{*}(56 / 40 ; 7.0)$, with $\mathrm{sstPO}_{2}=36.0 \mathrm{mmHg}$, corresponds to a slightly increased RBF input (within half the reference scatter, SM1-Table S1). RCM* (56/56; 5.3FU), with a $\mathrm{tPO}_{2}$ of $48.9 \mathrm{mmHg}$ reflects the influence of $\mathrm{LUM} \mathrm{PO}_{2}$ feed. The two other simulations correspond to oxygen feed set at the same value, low (40 $\mathrm{mmHg}$ ) or high $(48 \mathrm{mmHg})$, again within half the experimental scatter. With the exception of the $56 / 56 \mathrm{mmHg}$ feed, $\mathrm{RCM} \mathrm{PO}_{2}$ falls within the experimental range, and, interestingly, closer to the outer cortex value.

\subsubsection{Transient Conditions}

Beyond steady-state, we explored RCM behavior under transient conditions: when RBF input is set to zero (simulating ischemia) and when PTC and LUM oxygen feed inputs are set to zero (simulating anoxemia). For comparison with available experimental data (see SM1 Table S1), two variables are monitored vascular oxygen (as $\mathrm{PTC} \mathrm{PO}_{2}$ ) and average tissue oxygen; in addition, we monitor $\mathrm{Hb}$ saturation level).

Figure 8 (panel A) shows model $\left(\mathrm{RCM}^{*}\right.$ setting) "ischemic" time-course for capillary oxygen (PTC $\left.\mathrm{PO}_{2}\right), \mathrm{Hb}$ saturation $\left(\mathrm{Hb} \%\right.$ saturation), and tissue $\mathrm{PO}_{2}\left(\mathrm{tPO}_{2}\right)$, i.e., after $\mathrm{RBF}$ has been set to zero; the inset shows the saturation curve of $\mathrm{Hb}$ as a function of $\mathrm{PO}_{2}$. From $\mathrm{PO}_{2}$ decrease, we define ischemic (respectively anoxemic) oxygen "half-time" $\left(t_{50}\right)$, i.e., the time required for the variable to reach half of its initial value after $\mathrm{RBF}$ (resp. $\mathrm{PO}_{2}$ feed) has been set to zero. Panel B of Figure 8 summarizes RCM $t_{50}$ values (dark grey bars), and compares them to experimental references (light grey bars, see $B^{\circ}$ in SM1-Table S1). For capillary oxygen, ischemic oxygen half-life is $6.0 \pm 2.3 \mathrm{~s}$, as compared to the 
reference "micro-vessels" value (10.5 $\pm 4.1 \mathrm{~s}$, range 6-30), slightly faster than experimental values, but within SD (see panel B). NB: $t_{50}$ error estimated as model accuracy $(2.2 \mathrm{mmHg}$ ) divided by the local slope of $\mathrm{PO}_{2}$ decrease. For the tissue, ischemic $\mathrm{PO}_{2}$ half-life is $2.3 \pm 0.5 \mathrm{~s}$, to be compared to the reference value $4.7 \pm 2.5 \mathrm{~s}$ (see panel $\mathrm{B}$ ), although somewhat faster, the model reproduces the experimental cortical oxygen ischemic half-life within experimental SD. As expected, the $t_{50} \mathrm{of} \mathrm{Hb}$ saturation was similar to capillary $\mathrm{t}_{50}$ ( 5.7 vs. $6.0 \mathrm{~s}$; point-dotted line in panel A). Of interest, in view of the limited contribution of hemoglobin to model $\mathrm{PO}_{2}$, the ischemic response of $\mathrm{RCM}$ was also simulated in the absence of hemoglobin: without $\mathrm{Hb}$, tissue oxygen decrease is accelerated $\sim 5$-fold, to from 2.3 to $0.45 \mathrm{~s}$ (no experimental value available). In PTC patches alone, in the absence of $\mathrm{Hb}$, ischemic oxygen decrease is accelerated 10 -fold to $0.25 \mathrm{~s}$ (vs. $6.0 \mathrm{~s}$ when $\mathrm{Hb}$ is active). This indicates and confirms that $\mathrm{Hb}$ is well able to release oxygen, depending on conditions.

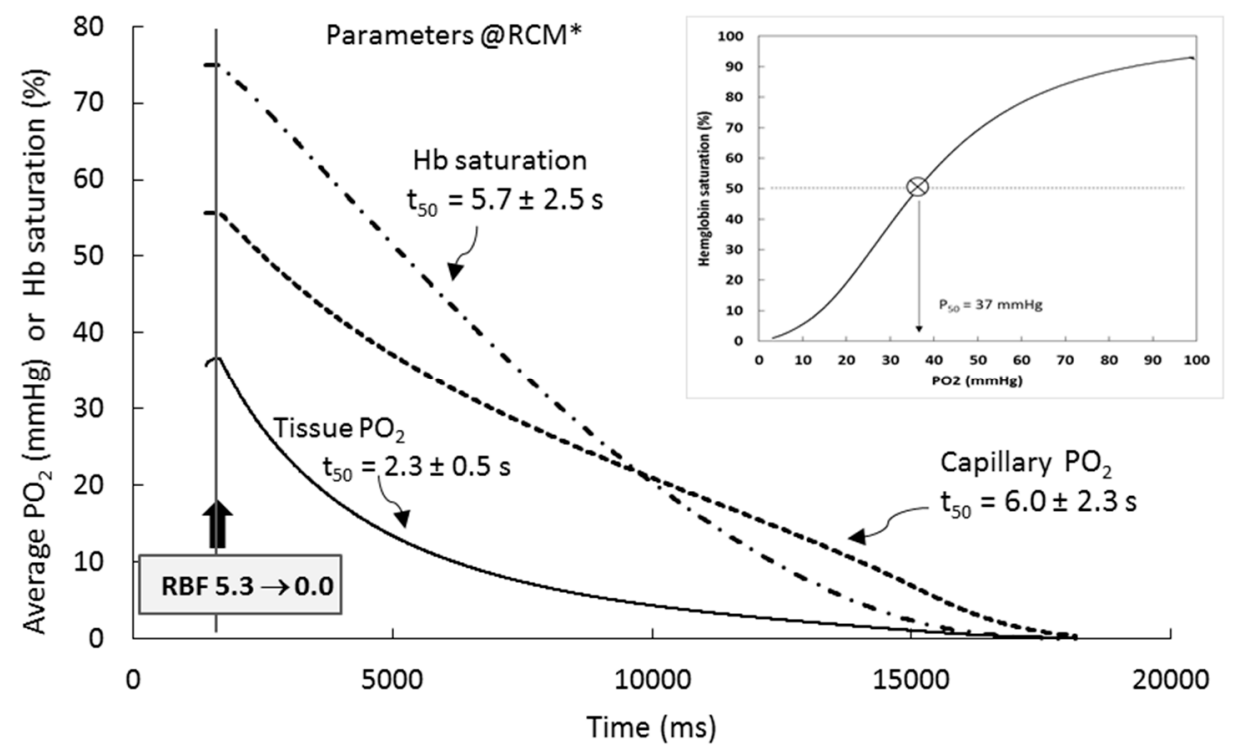

(A)

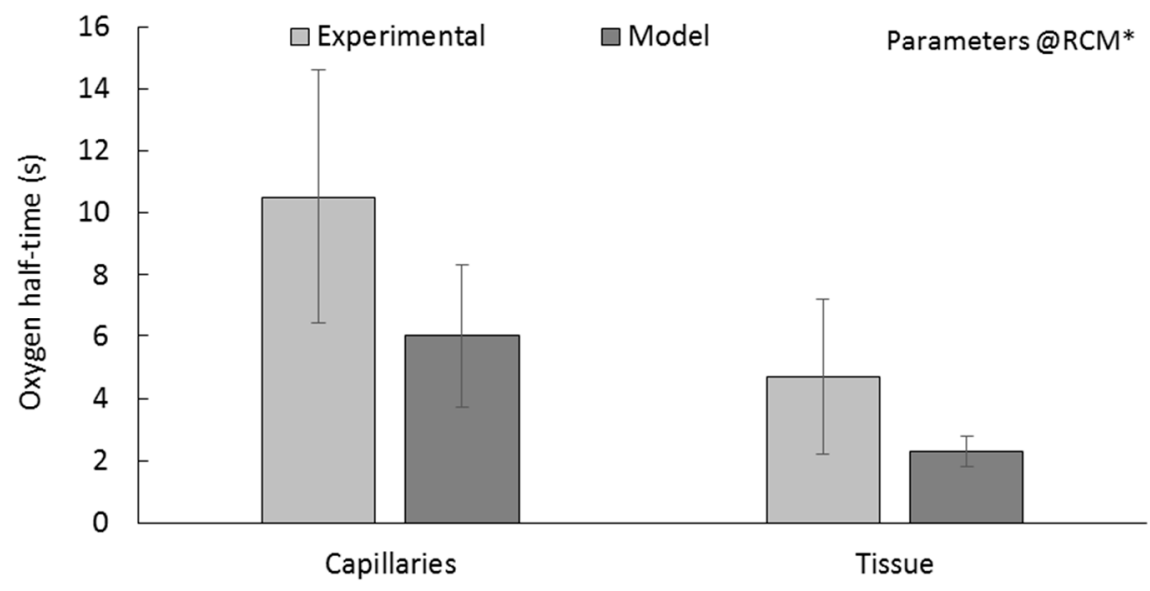

(B)

Figure 8. Ischemic half-time of oxygen in RCM. (A) At steady-state, RBF is set to zero, simulating "ischemia": capillary $\mathrm{PO}_{2}, \mathrm{Hb}$ saturation, and tissue $\mathrm{PO} 2$ are monitored Average tissue $\mathrm{PO}_{2}$ (black line) decreases progressively toward zero $\left(\mathrm{PO}_{2}<0.5 \mathrm{mmHg}\right)$, with a "half-time" ( $\left.\mathrm{t}_{50}\right)$ of $2.3 \pm 0.5 \mathrm{~s}$. Capillary $\mathrm{PO}_{2}$ ("PTC $\mathrm{PO}_{2}$ ", dotted line) and hemoglobin saturation (dot-point line) are also shown. Inset of panel A, Oxygen dissociation curve of hemoglobin, reconstructed from RCM simulation (50\% saturation, $37 \mathrm{mmHg}$ ). (B) Comparison of oxygen half-times for capillaries and for tissue to experimental values. 
Finally, we tested RCM under anoxemic dynamic conditions (not shown). When feeding $\mathrm{PO}_{2}$ inputs are set at $0 / 0 \mathrm{mmHg}$ from steady-state, oxygen drop is very fast, both in CTX ( $\mathrm{t}_{50} \sim 30-40 \mathrm{~ms}$ ) and in PTC ( $\left.\mathrm{t}_{50}=5-10 \mathrm{~ms}\right)$. These values decrease to $\sim 20 \mathrm{~ms}$ and $\sim 4 \mathrm{~ms}$, respectively, when $\mathrm{Hb}$ is de-activated.

\section{Discussion}

\subsection{Generalities}

The current understanding of physiological regulation of kidney oxygenation remains uncomplete, if not "rudimentary" [49]. So is the exact contribution of hypoxia-reoxygenation and tissue hypoxia in the initiation and progression of renal injury and disease. The lack can be appreciated by the decisive, still unanswered questions listed by expert reviewers (see $[1,2,49,50])$, as well as by the numerous modeling and simulation (MS) studies proposed since the late 90 's and early 2000's. From Lubbers and Baumgartl in 1997, to Lee and et al. in 2017 [10,12], some twenty modelling and simulation (MS) studies were dedicated to renal oxygenation (see $[26,27,50]$ for references), among which only four address the cortex $[10,22,35,51]$. Among the latter, none considers the cortical heterogeneity per se at the histological level, although Lee and et al.'s pseudo-3D model does integrate vessel compartments down to a 2D capillary-tubule model, able to predict the $\mathrm{PO}_{2}$ in the cortical tissue and micro-vessels [26].

Focusing on cortical oxygenation at the "histological" level, RCM is proposed as a complementary step to other MS approaches toward the full, yet to reach, description of renal tissue in response to ischemia-reperfusion (IR). Since oxygen deficit and oxygen reintroduction are primary events in this sequence, we developed RCM as a detailed model of oxygen distribution and consumption in the cortex. By construction and parameterization, it is an average cortical slice, representing mostly the proximal convoluted tubule (PCT, $\sim 60 \%$ the cortex), and secondarily the pars recta (PR, $\sim 25 \%$ ) and the distal tubule (DT, $\sim 15 \%$ ), with no segmental specificity at this stage. In order to accurately cope with the dynamics of the oxygen diffusion process, hemoglobin-oxygen interactions, and trans-tissular "convective" feeding flows, the time scale ranges from the millisecond to tens of seconds. In particular, RCM specifically considers the possible oxygen delivery by the tubular luminal flow to the adjacent epithelial cells. It is an altogether different endeavor than all other MS proposed up to now, which uses sophisticated mathematical MS tools at all uphill renal levels, but the tissue itself.

\subsection{Bibliographical Analysis for the Rat Kidney}

This work is the very first detailed, dynamic and physiologically-based model of renal cortical oxygenation at the cell-tissue level. Great care was dedicated to parameterize the model in terms of one specific species thanks to an extensive bibliographical search. The Rat species was chosen, as opposed to Man, Pig and Mouse, because it remains the most studied animal model in general ( 2 million rat publications in PubMed(C), as of October 2019), and for renal studies in particular.

\subsection{Sensitivity Analysis, Parameters, Inputs and Interactions}

\subsubsection{Parameters}

Sensitivity anaysis (SA) showed that the most influential parameters relate to morphometric features and reabsorptive/energetic processes. Based on SA, we calculated the "error" propagated in RCM for each parameter, given its variability. Most "sensitive" parameters (e.g., fractional transcellular fraction) exert a sizable influence on $\mathrm{sstPO}_{2}(1-3 \mathrm{mmHg})$. We conservatively estimate model error to $\sim 2 \mathrm{mmHg}$.

\subsubsection{Inputs}

RCM features three different inputs (RBF and $\mathrm{PO}_{2}$ feeds), and the $\mathrm{sstPO}_{2}$ output, in addition to patch-type $\mathrm{PO}_{2}$. Since we want to address cortex behavior under experimental situations far 
apart from "normal" physiology (e.g., ischemia, hypoxemia), inputs were scanned over ranges wider than references.

Except for electrode-based studies by Welch and et al. [52-54], intra-tubular and intra-capillary $\mathrm{PO}_{2}$ have not been measured, although uphill $\mathrm{PO}_{2}$ in glomerular capillaries has been measured in cases [48]. According to Welch and et al., tubular values are confidently measured as within the lumen ( $40 \mathrm{mmHg}$ ), but "capillary" values actually refer to sub-capsular "star vessels" (B. Welch, personal communication). Although they are comparable to (microelectrode) measurements of superficial glomeruli $\mathrm{PO}_{2}(\sim 46 \mathrm{mmHg})$ by Schurek and et al. [48], such values may or may not correspond to deeper, intra-cortical peritubular capillaries. Intra-microvascular (not necessarily capillary) values were determined by Ince and et al., using dual wavelength phosphorimetry $[55,56]$, yielding somewhat higher values (see SM1-Table S1). As reference input values, we used RBF 5.3 (mL/(min.gkw, or flow units, FU), $\mathrm{PTC} \mathrm{PO}_{2} 56 \mathrm{mmHg}$ and $\mathrm{LUM} \mathrm{PO}_{2} 40 \mathrm{mmHg}$. Relating to our working hypotheses and the luminal side of the tubules, it is noteworthy that indeed sizable levels of $\mathrm{PO}_{2}$ have been reported ( $40 \mathrm{mmHg}$ ), i.e., not very different from the capillary level $(56 \mathrm{mmHg}$, see above). This appears at variance, if not conflict, with the conventional hypothesis that luminal contribution to tissue oxygen is to be neglected [1]. A priori, one cannot see why luminal oxygen could not feed close-by epithelial cells.

At reference input values, and over a wide range around these, $\mathrm{PO}_{2}$ output is highly dependent on $\mathrm{PO}_{2}$ feeds, and weakly controlled by RBF, down to $1.5 \mathrm{FU}$. At lower RBF, tissue $\mathrm{PO}_{2}$ decreases rapidly towards zero. This means that, at least at normal $\mathrm{PO}_{2}$ feed, oxygen delivery remains greater than consumption as long as RBF is in the "quasi-normal" range (2.0-10.0 FU). On a patch basis, low RBF induces a continuous decrease of epithelial and interstitial $\mathrm{PO}_{2}$ (control slope $\sim 10$ and $\sim 1 \mathrm{mmHg} / \mathrm{FU}$, resp.), while capillary $\mathrm{PO}_{2}$ remains stable down to ischemia (0.01 FU). This is due to the high hemoglobin saturation $(\sim 76 \%$ at $56 \mathrm{mmHg})$.

Our model-based observation of the low control of cortical $\mathrm{PO}_{2}$ by RBF (see Figure 3 ) is reminiscent of experiments by Evans and et al., in Rabbit, showing that cortical $\mathrm{PO}_{2}$ is relatively stable $(-10 \%$, or $4 \mathrm{mmHg}$ ) under altered cortical perfusion ( $-30 \%$ from baseline) $[57,58]$; experiments in Sheep yielded similar results [57]. In rat, Emans and et al., evidenced a cortical $\mathrm{PO}_{2}$ decrease $(21 \%$, or $\sim 8 \mathrm{mmHg}$ ) upon systemic administration of angiotensin II and concomitant RBF reduction (-50\%) [49]. From these in vivo determinations, the authors suggested that a $\sim 30 \%$ threshold to RBF decrease applies before cortical hypoxia develops [49]. However, our model is an "ex vivo" construct in which organ and systemic regulations are missing. Nevertheless, the above suggest that the relatively weak control of RBF upon tissue $\mathrm{PO}_{2}$ might be a specific renal cortical feature, possibly related to the low extraction ratio. Again in vivo, cortical $\mathrm{PO}_{2}$ stability vs. perfusion went unmodified under increased consumption (2-fold, mitochondrial uncoupler, [57]): we simulated this situation by decreasing RBF 2-fold at a 2-fold increased $\mathrm{QO}_{2}$ : model $\mathrm{PO}_{2}$ remained within $1 \mathrm{mmHg}$ from control. Overall, the weak control of RBF over tissue $\mathrm{PO}_{2}(2.5 \mathrm{mmHg} / \mathrm{FU})$ is quantitatively comparable to experiments, slightly left-shifted towards RBF levels halved versus reference ("pre-ischemic" levels"). Within model limits, RCM implementation of local oxygen "delivery to consumption" appears to properly describe cortical oxygenation.

The second category of RCM input is represented by PTC and $\mathrm{LUM} \mathrm{PO}_{2}$ feeds. In RCM, under reference conditions, oxygen feeding by luminal $\mathrm{PO}_{2}$ dominates the control of tissue $\mathrm{PO}_{2}$ by a

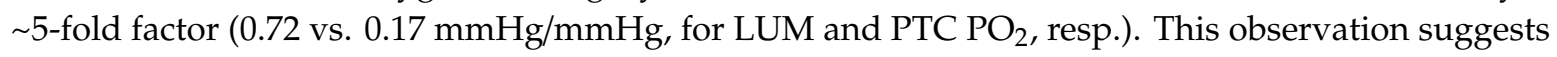
that, in in vivo reference conditions, oxygen delivered by the tubules could be of significance, and possibly higher than capillary oxygen delivery (see below for a detailed analysis). Under ischemic condition, capillary control increase three-fold, becoming dominant, with $0.51 \mathrm{mmHg} / \mathrm{mmHg}$ vs. $0.26 \mathrm{mmHg} / \mathrm{mmHg}$, for luminal side.

\subsubsection{Interactions between Inputs and Parameters}

Exhaustive scanning of all possible parameter-parameter and input-parameter interactions was not carried out. Nevertheless, simulations indicated that the parameter and inputs influences did 
not modify the relative importance of inputs control over $\mathrm{PO}_{2}$ output (feeding $\mathrm{PO}_{2}>\mathrm{RBF}$ ), nor the dominant contribution of luminal oxygen vs. capillaries.

\subsection{Verifications, Adjustments and Model Validation}

\subsubsection{Model Verifications}

For simplicity, we defined RCM as a 2D-idealized slice, plunging radially into the cortex. This choice of an idealized cortex as dictated by "histological" definition $(10 \mu \mathrm{m})$ as well as typical dimensions of tissue preparations $\left(1 / 10 \mathrm{~mm}^{2}\right)$. It was as comforted by our verifications that model tissue geometry reproduces rat cortical morphometric indexes.

The reference RCM tissue exhibits morphometric features of real cortex, including the fractional volume of the histological compartments [41]. This is important because, by definition and similarly to experimental measures, the average tissue $\mathrm{PO}_{2}$ integrates oxygen from all compartments, on a fractional volume basis.

From a functional standpoint, we verified flow distribution and oxygen processes. For perfusion, we verified that capillary and tubular volumic flows are adequately reproduced [59]. Oxygen-related processes were verified individually. For oxygen diffusion, one dedicated routine was code (Fick's first law). It was then verified to comply with known chemical physics), for both unidirectional and net diffusion (details are given in SM2).

The different terms of oxygen consumption were difficult to parameterize because most sources of information relating to whole kidney consumption, whereas RCM targets sub-compartments and cell types within the cortex. Moreover, renal regulations and experimental protocols generate additional experimental variability. Further, although in normal conditions transport-related cost dominates total $\mathrm{QO}_{2}$, non-transport (house-keeping) consumption gains increasing importance as transport load decreases, particularly under situations of interest such as ischemia. We extracted "capillary" consumption from [60-62]. This particular figure relates to capillaries and endothelial cells, but it is neither rat-specific (the sole exception in this work) nor kidney-specific, nor specific of renal peritubular capillaries. Then, we partitioned reference renal consumption down to house-keeping (EPI and PTC) and transport (EPI) related consumption of respiring patches. Numerous verifications were performed: (i) the final, effective consumption by RCM corresponds, within $25 \%$, to expected renal cortical consumption, (ii) independently, transport-related $\mathrm{QO}_{2}$ of EPI patches $(\sim 7 \mathrm{mM} / \mathrm{min})$ complies with rat proximal (and distal) transport capacity ( $\sim 26 \mathrm{mM} / \mathrm{min}$, under reference conditions), and (iii) as a corollary, these values indicate that the epithelial $\mathrm{Na}^{+}-\mathrm{K}^{+}$-pump would function at $\sim 30 \%$ of its maximal rate, which corresponds to $4-12 \mathrm{mM}$ intracellular $\mathrm{Na}^{+}$[63]; indeed, this value compares well to the intra-epithelial $\mathrm{Na}^{+}$concentration, in the 5-20 $\mathrm{mM}$ range [46].

Because simulation of RCM leads to the unexpected observation that, at least under reference conditions, hemoglobin contribution to tissue $\mathrm{PO}_{2}$ is limited, specific comments about hemoglobin verification, parameters, and equations, are called for. As opposed to $\mathrm{Hb}-\mathrm{O}_{2}$ equilibrium, very few descriptions of $\mathrm{Hb}-\mathrm{O}_{2}$ dynamics are available $[45,64,65]$ —and none for the rat. We use $\mathrm{Hb}-\mathrm{O}_{2}$ dynamic equations of Gutierrez [45] (see SM2 for details and justifications).

First, all equations from Gutierrez [45] were thoroughly verified by checking association/ dissociation dynamics, their relative influence upon the equilibrium constant, and the saturation curve. Second we performed additional verifications, including (i) the substitution of Gutierrez sigmoidal saturation equation by a simpler hyperbolic equation (as in [64,65]) and (ii) the implementation of a crude, "linear" hemoglobin (saturation as a linear function of $\mathrm{PO}_{2}$, half-point at $37 \mathrm{mmHg}, 100 \%$ beyond $74 \mathrm{mmHg}$; more details about $\mathrm{Hb}$ and equations used are given in SM2). 


\subsubsection{Physiological Adjustments}

Under $\mathrm{RCM}^{\circ}$ settings, model sstPO $\mathrm{PO}_{2}$ amounts to $\sim 34 \mathrm{mmHg}$, well within the experimental scatter. This constitutes one additional verification, and one step towards RCM validity. However, some parameters diverged from the normal regimen and required additional tuning.

With the $\mathrm{RCM}^{\circ}$ configuration, fractional "proximal" reabsorption, frPR, was set at reference value (51\%). However, real proximal fractional reabsorption is higher because experiments only quantify reabsorption based on the accessible proximal tubule length, leading to a significant underestimation. "Proximal" sodium reabsorption is considered to be $60-75 \%$ of filtered load (e.g., [46]). Fractional distal reabsorption amounts to some $9 \%$ (and $2 \mathrm{~mm}$ long). We adjusted both length and fractional reabsorption (12.4 mm and 75\%, resp.), so that fractional medullary reabsorption (absent from RCM), lies in its normal range $0.2-0.3$ [66].

The next tuned parameter is the fractional transcellular (or "active") epithelial sodium reabsorption. Renal proximal tubule carries vectorial transport, reabsorbing $\mathrm{NaCl}$ and water near-isotonically. Driven by the ATP-consuming basolateral $\mathrm{Na}^{+}-\mathrm{K}^{+}$pump, transepithelial reabsorption occurs via a panel of transcellular and paracellular pathways, involving filtered solutes (including bicarbonate), and relying on an axial distribution of processes [33,46]. These complex couplings allow the proximal tubule to reabsorb $\mathrm{Na}^{+}$with higher efficiency than expected from the sole action of the basolateral $\mathrm{Na}^{+}, \mathrm{K}^{+}$ pump (12-18 transported $\mathrm{Na}^{+}$per $\left.\mathrm{O}_{2}\right)[34,47,67]$.

For reference, we used an axially-averaged value for transcellular fraction ( 0.81 , see SM1-Table S4). This corresponds to $\sim 18-20 \mathrm{Na}^{+} / \mathrm{O}_{2}$, a value well below the 24-30 experimental ratio for PT or the cortex [31,47], equivalent to a transcellular fraction $\sim 0.46-0.63$. Finally, we increased the $\mathrm{ATP} / \mathrm{O}_{2}$ ratio (4.5 to 5.5), assuming that the cortex energetic metabolism and Oxphos are optimally fed $[68,69]$.

\subsubsection{Model Validation}

Tissue $\mathrm{PO}_{2}$ output of $\mathrm{RCM}^{\circ}\left(\mathrm{BV}^{\circ}\right)$ and $\mathrm{RCM}^{*}$ (fine-tuned) is well within reported experimental values of cortical $\mathrm{PO}_{2}$. This was expected because $\mathrm{RCM}$ and its settings are based on careful bibliography, analyses, and verifications.

Steady-state validation (tissue): RCM individualizes two oxygen inputs, capillaries, and tubules. Accordingly, most simulations were run with $\mathrm{PTC}_{\text {LUM PO}}$ set at their reference values, $56 / 40 \mathrm{mmHg}$ ). In most renal studies, oxygen is measured either: (i) with polarographic, Clark-type microelectrodes (e.g., [12,54]) or fluorescence optodes (as in [16,70]), yielding average tissue $\mathrm{PO}_{2}$, or (ii) vascular-confined oxygen-sensitive phosphorescent dyes, addressing vascular and micro-vascular $\left.\mathrm{PO}_{2}[55,56]\right)$. Despite such a variety of methods, careful cross-examination of references and data with the (Rat-based) mathematical model by Gardiner and et al. [24,25], indicates that "peri-glomerular" $\mathrm{PO}_{2}$, including post-glomerular PTC, most probably lies in the $\sim 40-50 \mathrm{mmHg}$ range, at least in superficial cortex and nephrons (45 $\pm 6 \mathrm{mmHg}$ in [54], $46 \pm 13 \mathrm{mmHg}$ in [48]). Scanning this range, yielded $\mathrm{sstPO}_{2}$ well corresponding to reference values, $\mathrm{RCM}^{*}(56 / 40 ; 5.3)$ producing a tissue $\mathrm{PO}_{2}$ of $36 \mathrm{mmHg}$. Well within experimental scatter, the latter value lies closer to the outer cortex, possibly because the inner cortex represents less than $25 \%$ of the cortex and most reference values derive from experiments relating to the outer cortex and superficial nephrons.

In 2001, Welch and coll. provided the first measurements of intraluminal $\mathrm{PO}_{2}$, in addition to post-glomerular and interstitial $\mathrm{PO}_{2}$ [52-54], thus addressing two out of the four $\mathrm{RCM}$ compartments. We used their data to try and complete RCM validation on a local, patch basis (data not shown). Briefly, when set at experimental values of input $\left(45 / 39 \mathrm{mmHg}, 5.1 \mathrm{FU}\right.$,), model sstPO $\mathrm{P}_{2}$ was 34-35 mm $\mathrm{mg}$, again within experimental scatter; note however that since average tissue PO2 is not reported in [54] no comparison is possible. On the other hand, as expected, PTC remained close to its feed value $\left(44.7 \mathrm{mmHg}\right.$ ) and $\mathrm{LUM} \mathrm{PO}_{2}$ decreased to $34.9 \mathrm{mmHg}$, a value differing by $\sim 3 \mathrm{mmHg}$ from the reported one (39.0 $\pm 4 \mathrm{mmHg}$ SD, "PT" in Table 2 of [54]). Similarly, simulated interstitial $\mathrm{PO}_{2}$ (37.5 mmHg, INT patches) was markedly lower (by $4-5 \mathrm{mmHg}$ ) than reported (42 $\pm 7 \mathrm{mmHg} \mathrm{SD}$; "OC", Table 2, [54]). Overall, RCM did not "satisfactorily" predict the "local" experimental values from [54]. In addition to 
RCM limitations (see below), in experiments from [54], the "interstitial" compartment is said to be "not so precisely defined", the average $\mathrm{PO}_{2}$ of the tissue is not given, and values pertain only to accessible, superficial nephrons, with no definite segmental positioning. Thus, disappointing as they seem, these observations result from a combination of experimental uncertainties and model-related limitations.

Dynamic validation: In order to validate RCM under transient conditions, we determine two dynamic variables. First, the "ischemic" oxygen half-life, the time required for the average capillary and tissue $\mathrm{PO}_{2}$ to reach $50 \%$ of their initial value, when RBF is set to zero (thus capillary and tubule volumic flows). Second, by analogy, the "anoxemic" half-time, when oxygen feed is set to zero (PTC and LUM). Very few "dynamic" experimental data are available, and they relate to in vivo tissue and/or vascular $\mathrm{PO}_{2}$, with different protocols and methodologies (e.g. [71]). To the best of our knowledge, the only available data are summarized in SM1, for the (micro-)vascular compartments [56,72], and for the average cortical tissue $[11,73]$. Despite the important gap between the above experimental conditions for reference values and the model level, RCM proved able to reproduce quite well (within experimental range) ischemic and hypoxemic half-times), both in terms of average tissue and in terms of micro-vessels $\mathrm{PO}_{2}$. Importantly, $\mathrm{Hb}$ omission accelerates oxygen ischemic decreased 5 -fold in the tissue, 10-fold in PTC's. These figures cannot be "validated" per se due to the absence of experimental determinations. For the same reason, RCM anoxemic half-times, although accelerated in the absence of $\mathrm{Hb}$, cannot be validated either. Finally, RCM simulated ischemic time to reach $10 \%$ of initial $\mathrm{PO}_{2}(\sim 17 \mathrm{~s})$ proved reasonably comparable to experimental data, both for tissue and for vessels [56,72]. Overall, RCM dynamic behavior corresponds well to available data. With regard to the limited contribution of hemoglobin on model $\mathrm{PO}_{2}$ (in reference conditions), it is important to stress that $\mathrm{Hb}$ omission consistently accelerated equilibration transients. At this point, RCM was considered validated, both under steady-state and transient conditions.

\subsection{Capillary and Hemoglobin Versus Luminal Oxygen Delivery}

Two related and counter-intuitive observations were made with RCM, which seemingly contradicts the usual capillary and hemoglobin paradigms in terms of oxygen delivery. First, hemoglobin exerts a weak influence on $\mathrm{sstPO}_{2}$ under reference conditions. A priori counter-intuitive, this model-based observation parallels the known excess oxygen supply to the kidney, particularly to the cortex. At $\mathrm{RBF}^{\circ}$, the capillary flow is $\sim 23 \mathrm{~nL} / \mathrm{min}$, equivalent to a PTC residence time of $\sim 2 \mathrm{~ms}$. Based on this important capillary variable, we reasoned that the a priori expected $\mathrm{Hb}$ contribution to model $\mathrm{PO}_{2}$ could be "unmasked" by increasing residence time. Indeed, we observed that below $2.0 \mathrm{FU}(8 \mathrm{~nL} / \mathrm{min}, \mathrm{RT} \sim 5 \mathrm{~ms})$, $\mathrm{Hb}$ contribution to tissue $\mathrm{PO}_{2}$ started to increase, to reach $\sim 12 \mathrm{mmHg}$. Other manipulations, such as increasing $\mathrm{QO}_{2}$ (2-fold), did not modify $\Delta \mathrm{Hb}$. Second, as already mentioned, under normal perfusion, about $80 \%$ of model $\mathrm{PO}_{2}$ is determined by tubular lumen, whereas capillaries contribute $\sim 20 \%$. PTC contribution progressively takes over when RBF is decreased. These exploratory observations and verifications proved robust with respect to tissue geometry and parameters (data not shown). In any case, they likely relate to capillary "blood" (or erythrocytes) transit time. Interestingly, to the best of our efforts, we could not find any experimental demonstration that the presence of $\mathrm{Hb}$ in normal kidney perfusion is associated with higher values of tissue $\mathrm{PO}_{2}$.

\subsection{Can Really Luminal $\mathrm{PO}_{2}$ Delivery be of Significance?}

In view of the above, after numerous verifications, this question became pregnant, even more so because, again to the best of our knowledge, the possibility of any significant oxygen delivery via the tubules has been largely ignored. This is surprising, at least for two reasons. First, bibliographical analysis shows that oxygen is present in the tubular lumen, at levels comparable to micro-vessels and capillaries, 30-50 mmHg according to [52-54] (SM1-Table S1). What would prevent such dissolved oxygen to diffuse toward epithelial cells? Second, because urinary $\mathrm{PO}_{2}$, well known to be far from zero (in the $10-20 \mathrm{mmHg}$ range) is considered as a reasonable, measure of medullary $\mathrm{PO}_{2}[74,75]$. 
To repeat ourselves, the standard view about tissue oxygenation, is merely that capillaries and hemoglobin are the sole oxygen providers. In the case of the kidney, it might be an "a priori" requiring to be demonstrated. Our model-based observations suggest that it may not be the case. In their model of "cortical oxygenation", Lee and et al.'s model only allows capillaries to deliver oxygen (see Figure 2 in [26]); incidentally, the possible advective removal of oxygen by the flowing tubular fluid is also ignored. Simple calculations, ignoring $\mathrm{PTC}_{2}$ delivery and using reference values (plasma sodium $142 \mathrm{mM}$, SNGFR $33 \mathrm{~nL} / \mathrm{min}$, luminal $\mathrm{PO}_{2} 40 \mathrm{mmHg}$ ) yield a single nephron $\mathrm{Na}^{+}$load of $4.5 \mathrm{nmoles} / \mathrm{min}$, versus a simultaneous oxygen load of $0.002 \mathrm{nmoles} / \mathrm{min}$ per glomerulus. As such, this $\sim 2300$ mole-to-mole ratio certainly does not support luminal $\mathrm{PO}_{2}$ as a possible oxygen source. In a recent commentary, Evans and Ow mention that glomerular filtrate oxygen contributes to less than $1 \%$ to epithelial oxygen tension [76]. This could be true; but most probably not always and not everywhere along the tubule. The calculations developed below support this notion. Taking into account a 15 -factor ( $3 \mathrm{Na}^{+} /$ATP for the $\mathrm{Na}^{+}-\mathrm{K}^{+}$pump, and $5 \mathrm{ATP} / \mathrm{O}_{2}$ for Oxphos) reduces the luminal $\mathrm{Na}^{+}$load/O $\mathrm{O}_{2}$ load ratio to $\sim 160$; considering the average cortical transcellular/paracellular epithelial reabsorption fractions $(0.81 / 0.19)$ and the bicarbonate effect" (cortical average, $1.15[14,46])$ further reduces the ratio to $\sim 110 \mathrm{Na}^{+}$per $\mathrm{O}_{2}$-still largely unfavorable. The total reabsorptive work-load is distributed, although not equally, all along the tubule length $(\sim 10 \mathrm{~mm}$, for the proximal tubule). Based on the segmental distribution of maximal $\mathrm{Na}^{+}-\mathrm{K}^{+}$pump activity (PCT/PR or S1/S2/S3 [46,77-80]), the average weighed fractional tubular reabsorption amounts to $\sim 25 \%$ per millimeter. In other words, each millimeter of PT would have a minima 1 available $\mathrm{O}_{2}$ to reabsorb $\sim 11 \mathrm{Na}^{+}$-still insufficient. But since the lumen-epithelial exchange surface area (brush-border membrane, dedicated to reabsorption) is at least 10-fold higher than the capillary-epithelial contact, the lumen-to-epithelia $\mathrm{O}_{2}$ diffusive fluxes are in fine comparable to the capillary-epithelial exchanges (all other factors considered equal). This analysis substantiates the notion that the luminal delivery of oxygen cannot be ignored and can even be substantial. Unplanned, the notion progressively imposed itself. Quite logically, this is exactly what we observed with RCM, whatever parametric/input configuration. Finally, the predominant control of tissue $\mathrm{PO}_{2}$ by luminal versus capillary $\mathrm{PO}_{2}$, appears directly related to quasi-independence of tissue $\mathrm{PO}_{2}$ versus hemoglobin (in reference conditions).

Again, these observations came out as totally unexpected because a priori, we all had the "common sense" notion that hemoglobin provides oxygen to consuming tissues, such as muscles or brain (e.g., [81-83])—even though, of course, it is the dissolved oxygen which in fine diffuses towards the tissue. We were so puzzled that we performed extensive, additional verifications, including numerous controls and verifications of hemoglobin equations, parameters and behavior (see above). In all cases, $\mathrm{Hb}$ exerted practically no influence upon tissue $\mathrm{PO}_{2}(<0.1-0.2 \mathrm{mmHg})$.

In order to confirm that our observations were indeed not artifacts, and specific of the renal cortex, we constructed "muscle-oriented" variants of RCM. These "muscle models" were designed with the same capillary density as their renal counterpart; in addition, i) all luminal patches were replaced by "epithelial" patches, and ii) all "epithelial/muscle" patches were attributed sub-maximal muscle $\mathrm{QO}_{2}$ (1.0-5.0 mM/min; [82-86]). Finally, the capillary factor was adjusted so that apparent blood velocity ranged within muscle reference values $(0.1$ to $2.0 \mathrm{~mm} / \mathrm{s}[82,87]$. Under these muscle-like settings, hemoglobin contribution to tissue $\mathrm{PO}_{2}$ was $\sim 2-8 \mathrm{mmHg}$. To the best of our research, no equivalent renal tissue $\mathrm{PO}_{2}$ measurements in the absence of hemoglobin was found. Of note, even at the "high" $5 \mathrm{~mm} / \mathrm{s}$ apparent velocity (perfusion "RBF" set at $5 \mathrm{FU}$, capillary adjusting factor set at $1.0), \mathrm{Hb}$ contribution was already increased $5-10$ fold in "muscle-model" vs. RCM (to $\sim 1.0 \mathrm{mmHg}$ ). No further attempt was made here toward a more detailed representation of muscle tissue. Certainly, the emergence of a strong $\mathrm{Hb}$ control over tissue $\mathrm{PO}_{2}$ (as seen in $\mathrm{RCM}$ and "muscle-models") relates to the capillary residence time (typically $100-1000 \mathrm{~ms}$ ), a quantity driven by the apparent blood velocity. It is well known that the capillary transit time constitutes a kinetic barrier to oxygen delivery, and that the higher its value the higher the oxygen delivery [45,65]. With RCM, this effect was seen in all parametric configurations tested (see below). A final word of caution. As mentioned, RCM is 
parameterized from bibliographical references, most of which relate to outer cortex. In addition, at this stage of its development and because of its simple 2D geometry, RCM averages segmental tubular characteristics and does not allow for a more accurate dissection of luminal oxygen delivery. For instance, should the early parts of PCT (the so-called S1 segment, about one third of PT length) exhibit a higher fractional reabsorption than the average value considered above [46,77-80], it would consume in proportion more oxygen, leaving less for subsequent segments.

It remains that our model and the above reasoning strongly suggest that the bulk of normal renal cortical oxygen originates from filtered oxygen at the glomerular level, not from capillaries. This is perhaps not that surprising, if one considers that the main physiological function of cortical peritubular capillaries is to reabsorb the enormous amount of proximal filtrate (water, $\mathrm{NaCl}$, bicarbonate etc.). Perhaps less obvious is the suggestion that in doing so, perhaps because of doing so, peritubular capillaries do not provide much of the oxygen required for this reabsorption, a task seemingly devoted to the tubules. One incident advantage of such a situation would be that more capillary ( $\mathrm{Hb}$ bound) oxygen would be thus available for the hypoxic medulla (see $[30,88])$.

\subsection{Model Simplifications, Limitations, and Issues}

\subsubsection{RCM is a Simplified 2D Description}

RCM is a 2D, multi-capillary, modified Krogh's model [81]. Its 2D geometry is the first and most important simplification. Exhibiting an apparent disorder (e.g., "cortical labyrinth"), the cortical tissue is complex and heterogeneous, even more so if compared to the highly structured medulla $[21,27,29,30]$. This is why, in this ab initio development, we did not embark into 3D tubulo-vascular cortical "reconstruction" - which, to the best of our knowledge, no study addressed up to now. The 2D representation and limited thickness prevent the accounting for known (and putatively consequential to oxygen distribution) axial $\mathrm{PO}_{2}$ gradients $[45,81]$. In addition, the topological continuity along tubules and capillaries is broken. We performed exploratory simulations with axially, parallel configured tubules and capillaries, still two-dimensional. Although not as accurately parameterized nor verified as was RCM, all simulations attempts with these "longitudinal cortical models" (30-40 mmHg average $\mathrm{PO}_{2}$ ) ended at confirming the low control of $\mathrm{Hb}$ and $\mathrm{PTC}$ over average tissue $\mathrm{PO}_{2}$ (data not shown). It nevertheless remains that the limited length for "convection" imposed by the $10 \mu \mathrm{m}$-thickness of RCM most likely overestimates the contribution ratio of tubules to capillaries in terms of oxygen delivery. Finally, RCM likely represents more accurately the outer and mid cortex, than the deep cortex and the cortico-medullary junction. Since IR-induced necrosis is known to develop radially, from the CMJ toward the capsule it will be of utmost importance to specify and parameterize this key area. At this point, several of the required experimental data are missing to confidently do so.

4.7.2. RCM Represents Capillaries but Does Not Implement Capillary Hemodynamics nor Circulating Cells, Including Erythrocytes

We partially addressed this limitation with the "capillary hemodynamic factor" allowing to impose more physiological capillary "blood" velocities (see above). The conclusions are drawn from this crude, phenomenological correction obviously call for physiologically-based modeling of the utterly complex capillary hemodynamics, taking into account local "tube" hematocrit, viscosity, flow, velocity, and dimensions. Moreover, the mechanical (deformation) and biochemical (ATP release, $\mathrm{Hb} / \mathrm{NO}^{\circ}$, etc.) interactions between erythrocytes and the capillary/endothelial wall, all known to facilitate oxygen delivery, are ignored in our primitive construct $[89,90]$.

\subsubsection{RCM Features Non-Resistive, Non-Pressure Driven Flows}

Our model does not implement mechanic nor hemodynamic phenomena: blood and luminal flows are not resistive (i.e., not pressure-driven), tubules are not compliant [33], and hydrostatic and oncotic pressures, as they drive reabsorption towards the capillaries, are ignored. When perfusion is 
stopped and filtration ceases, local reabsorption can proceed for some time (as occurs in RCM), perhaps 10-15 s (see Discussion in [11]), but, in the same time, tubules and capillaries will collapse, which does not occur in current RCM. The omission of flow-pressure relationships has another consequence: simulations performed at decreasing perfusion, do so by ignoring the reduction of perfusion pressure, thus assuming that the glomerular filtration pressure remains above its cut-off pressure $(\sim 18 \mathrm{mmHg})$. In situ, below such threshold, capillary perfusion (and associated oxygen delivery) can persist while luminal flow is arrested. From this standpoint too, RCM likely overestimates the contribution ratio of tubules to capillaries in terms of oxygen delivery, although this restriction does not apply at normal RBF.

\subsubsection{Renal and Systemic Regulations Are Missing}

Renal regulations are purposedly missing, including autoregulation and tubulo-glomerular feedback, and by definition systemic influences. Such simplifications set limits to the conclusions that can be drawn, particularly from RCM-simulated ischemia.

\subsubsection{RCM Ignores Other Cortical Potential Sources of Oxygen}

RCM ignores arterioles and glomeruli, and higher-order vessels as well, structures known to exhibit $\mathrm{PO}_{2}$ closer to arterial $\mathrm{PO}_{2}(\sim 100 \mathrm{mmHg})$, in any case markedly higher than the "average cortex". Because the corresponding $\mathrm{PO}_{2}$ gradient would be favorable, it can be argued that such potential sources could indeed deliver oxygen to nearby consuming tubules (see [26]). In RCM, we explored the influence of such oxygen sources by setting the $\mathrm{PO}_{2}$ variable of selected patches (up to $5 \times 5$ regions) to the range of reported values $(50-100 \mathrm{mmHg}$ ). These exploratory simulations showed that the influence of such high oxygen sources restricted to less than $1-2 \mathrm{mmHg}$, within a $30 \mu \mathrm{m}$-radius (single patch or multiple-patch area). Identical observations were made when neighboring consumption was either drastically reduced or increased. Similarly, the local "closing" of a given capillary (simulating a local thrombus or nearby leukocyte adhesion), or for that matter of an entire tubule (simulating intratubular casts), did not extend its influence upon oxygen farther than its immediate neighbors $(\sim 10-30 \mu \mathrm{m})$. This observation was to be expected, as a direct consequence of oxygen diffusion physics, and it has been confirmed by others that the influence of oxygen sources, including capillaries, ranges 20-30 $\mu \mathrm{m}[91]$.

\subsubsection{Defective Validation Versus Luminal and Interstitial Measurements (One Study)}

Notwithstanding experimental limitations to this seminal and important study, the defective validation versus luminal and interstitial $\mathrm{PO}_{2}$ measurements [54], stresses that $\mathrm{RCM}$, as a model, is uncomplete. As mentioned, RCM currently "average" renal cortical components, both "horizontally" (PCT, PR, DT) and "vertically" (superficial, median and juxtamedullary nephrons). A more specific, region and segment-based parameterization, or a $3 \mathrm{D}$ construct should improve RCM discriminating power. Experimental data would be surely missing, although new and more accurate oxygen measurement methodologies (e.g., segment-specific) are becoming available (see [92,93]).

\subsection{Perspectives and Conclusion}

\subsubsection{Time Scale, Energetic Metabolism and Tissue Response to IR}

RCM was developed to address oxygen dynamics in time ranges pertaining to convection, diffusion, and consumption (ms to seconds), at the histological scale (tens of $\mu \mathrm{m}$ ). Such a short time scale cannot address IR events, which develop in minutes (ATP drop or endothelial activation), hours (leukocyte infiltration, cell death), days (tissue repair) and weeks/months to years (fibrosis). As an anticipation, an oxygen steady-state, ATP dynamic, version of RCM has been implemented, able to run with 5 to 60 min time-step, and yielding similar $\mathrm{PO}_{2}$ as the present model, within $2-3 \mathrm{mmHg}$, across the whole ranges of inputs. Finally, RCM does not cover the regulatory processes allowing the kidney to react and adapt to ischemic/hypoxic events. RCM refinement with the addition of more detailed 
cellular functionalities such as oxidative/nitrosative stress and cell/death/repair is a key requirement to IR and IRI description.

\subsubsection{Towards Renal IR Injury}

As a whole, our results suggest that in the renal cortex the "oxygen feeding unit" for a tubule, is actually constituted by its own lumen and nearby capillaries. This is different from other, more "structured" organs such as the striated muscle, in which the feeding unit "restricts" to capillaries [81, $84,94]$. In this reasoning, it appears that unless it is severely widespread, tissue fibrosis will not be a major impediment to oxygen delivery at the local scale—as long as tubular (and perhaps capillary) flow is sufficient, i.e., as long as glomerular function and filtration is maintained. With RCM, we performed exploratory simulations supporting this idea (by manipulating histological diffusion coefficients), but this is an important point, that requires to be specifically addressed, and which will strongly depend on the fibrosis-inducing etiology (e.g., glomerular vs. tubular diseases).

It is often hypothesized that capillary rarefaction and/or fibrosis, both deleterious consequences and hallmarks of renal IR injury, increase diffusion distance and reduce oxygen availability [95]. From our observations, it would appear that, at least at the local scale and in "normal" conditions, and, again, as long as the "tubule/capillaries" couple is present and properly perfused, relevant tubular cells will be oxygenated and the transepithelial reabsorptive processes will occur. It has been observed in IR-related renal pathologies that glomerular degeneration, tubular atrophy, and interstitial fibrosis, correlate with capillary rarefaction [96,97]. This suggests that local hypoxia observed with capillary loss (as in [96], with pimonidazole) might not be due to capillary rarefaction, but to some reduction in tubular flow. RCM simulations, ignoring etiology and regulations, nevertheless yield a quantitative effect of luminal flow, amounting to $10-30 \mathrm{mmHg}$, far sufficient for chemical detection with pimonidazole [98].

\subsubsection{Hypothermia and Oxygen Carriers}

With oxygenation, temperature is one key parameter in renal graft preservation. Based on cell metabolic reduction, hypothermic storage is the main strategy to minimize ischemic (and/or reperfusive) injuries [3,99]. RCM hemoglobin stabilizes cortical oxygen and slows the ischemic $\mathrm{O}_{2}$ disappearance; exploratory experiments where parameters and processes were adjusted at their $4{ }^{\circ} \mathrm{C}$-equivalent showed that low temperature stabilizes tissue oxygen. Thus RCM could also be used as a helping tool to analyze the role of temperature on the one hand, and hemoglobin and various other oxygen carriers, on the other hand $[3,99]$.

\subsubsection{Erythropoietin}

The low control of cortical $\mathrm{PO}_{2}$ by hemoglobin may appear surprising, considering that the kidney is the main producer of erythropoietin (Epo), in adults [100,101], and that the specific stimulus for Epo expression is considered a reduction in local $\mathrm{PO}_{2}$ (cell/tissue?) [101]. However, renal perfusion and hormonal influences have been also been shown to be at play, if not determinant in cases. Moreover, the specifics (amplitude, kinetics and exact localization) of Epo production are still unraveled, especially in terms of local $\mathrm{PO}_{2}$, despite the identification of specialized interstitial fibroblasts, the so-called renal Epo-producing (REP) cells, localized in the juxta-medullary region of the cortex, CMJ [102,103]. Current RCM does not target this region. We hypothesize that, when properly unraveled, the CMJ region will show a local, specific regimen of oxygen regulation. Certainly, juxta-medullary model variants would be of help in that matter.

\subsection{Conclusions}

We have developed and validated RCM, the first dynamic model of renal cortical oxygenation at the cell-tissue level. Consistently parameterized for the rat, RCM is more of a "knowledge model" at this stage, but it already helps a better and quantitative understanding of cell-tissue level interactions involved in local oxygen delivery and consumption. As such, it will allow for the examination of 
mechanistic or etiologic hypotheses. Within acknowledged limits, RCM simulations lead us to propose the challenging hypothesis of a significant contribution of luminal oxygen to cortical oxygenation. Along with progressive refinements, RCM will constitute a quantitative tool to address IR-related pathophysiological and therapeutic aspects. Finally, RCM could constitute a basis for tissue-level modules required for multi-scale/multi-dynamic models addressing renal function, at the organ or systemic levels $[102,103]$ during and after ischemia-reperfusion events.

Supplementary Materials: Supplementary Materials can be found at http://www.mdpi.com/1422-0067/20/24/ 6246/s1. Supplementary Materials File 1 (SM1); Supplementary Materials File 2 (SM2).

Author Contributions: Conceptualization, P.H.; Data curation, J.K. and P.H.; Formal analysis, F.G. and P.H.; Funding acquisition, T.H.; Investigation, V.A., J.K., P.H. and F.G.; Methodology, V.A. and J.K.; Resources, T.H.; Software/model coding, V.A.; Supervision, P.H.; Validation, F.G. and P.H.; Writing-original draft, P.H.; Writing-review \& editing, P.H.

Funding: This research received no external funding.

Acknowledgments: This work was performed in INSERM U1082-IRTOMIT research unit (dir. T Hauet). V. Aubert was supported by a doctoral joint grant (French Ministry of Research MENRT and Région Poitou-Charentes). P. Hannaert salarial cost is supported by the French CNRS. We acknowledge W. Welch for kindly answering our questions about their electrode positioning and capillary oxygen measurements in Rat renal cortex (Welch et al., 2001). We gratefully thank A Edwards and SR Thomas for insightful comments, as well as for providing useful sources. We thank N. Quellard and B. Fernandez (U1082 and Cytopathology Department, CHU Poitiers, JM Goujon) for providing and helping with lab-made rat cortical mounted sections (counting and geometry measurements of capillary and tubular sections).

Conflicts of Interest: The authors declare no conflict of interest.

\section{Abbreviations and Symbols Used}

$\begin{array}{ll}\mathrm{ABM} & \text { Agent-based modeling } \\ \mathrm{AKI} & \text { Acute kidney disease } \\ \mathrm{AV} & \text { Arterio-venous } \\ \mathrm{BV}\left(\mathrm{BV}^{\circ}\right) & \text { Biological (or Bibliographical) value (reference BV) } \\ \mathrm{CBF} & \text { Cortical blood flow } \\ \mathrm{CKD} & \text { Chronic kidney disease } \\ \mathrm{CFF} & \text { Capillary flow factor } \\ \mathrm{CMJ} & \text { Cortico-medullary junction } \\ \mathrm{CVF} & \text { Capillary volumic flow } \\ \mathrm{DT} & \text { Distal tubule } \\ \mathrm{EPI} & \text { Epithelial patch } \\ \mathrm{EPO} & \text { Erythropoietin } \\ \mathrm{ESA} & \text { Exchange surface area } \\ \mathrm{fCapBr} & \text { Capillary branching factor } \\ \mathrm{FF} & \text { Filtration fraction } \\ \mathrm{frPR} & \text { Fractional proximal reabsorption } \\ \mathrm{GFR} & \text { Glomerular filtration rate } \\ \mathrm{GUI} & \text { Graphic user interface } \\ \mathrm{Hb} & \text { Hemoglobin (free of oxygen) } \\ \mathrm{HbO} 2 & \text { Oxygenated hemoglobin } \\ \mathrm{Hbt} & \text { Total hemoglobin } \\ \mathrm{Hta} / \mathrm{e} & \text { Hematocrit (afferent/efferent) } \\ \mathrm{HK} & \text { House-keeping } \\ \mathrm{INT} & \text { Interstitial patch } \\ \mathrm{IP} / \mathrm{DP} & \text { Independent/Dependent parameter } \\ \mathrm{IR} & \text { Ischemia-reperfusion } \\ \mathrm{IRI} & \text { Ischemia-reperfusion injury } \\ \mathrm{k} \text { 'c } & \text { Association coefficient for the } \mathrm{Hb} / \mathrm{O}_{2} \text { reaction } \\ \mathrm{kc} & \text { Dissociation coefficient for the } \mathrm{Hb} / \mathrm{O}_{2} \text { reaction } \\ & \end{array}$




\begin{tabular}{|c|c|}
\hline LUM & Luminal patch \\
\hline MS & Modeling and simulation \\
\hline Nap & Plasma $\mathrm{Na}^{+}$concentration \\
\hline nHill & Hill's cooperativity index \\
\hline $\mathrm{N}_{\text {tot }}$ & Nephron density \\
\hline Oxphos & Oxidative phosphorylation \\
\hline $\mathrm{OpNe}$ & Operational nephron \\
\hline $\mathrm{P}_{50}$ & Half-saturation $\mathrm{PO}_{2}$ for hemoglobin \\
\hline $\mathrm{PO}_{2}$ & Oxygen partial pressure \\
\hline PT & PT, proximal tubule \\
\hline PCT & PCT, proximal convoluted tubule \\
\hline PTC & PTC, peritubular capillary patch \\
\hline PU & Patch units \\
\hline QKDB & Quantitative Kidney DataBase \\
\hline $\mathrm{QO}_{2}$ & Oxygen consumption \\
\hline RBF & Renal blood flow \\
\hline $\mathrm{RCM}$ & Renal cortical model \\
\hline RSC & Relative sensitivity coefficient \\
\hline SNAPR & Single-nephron absolute proximal reabsorption \\
\hline SNEABF & Single-nephron efferent arteriole blood flow \\
\hline SNFLNa & Single-nephron $\mathrm{Na}^{+}$load \\
\hline SNGBF & Single-nephron blood flow \\
\hline SNGFR & Single-nephron GFR \\
\hline $\mathrm{sstPO}_{2}$ & Steady-state average model $\mathrm{PO}_{2}$ \\
\hline TFF & Tubular flow factor \\
\hline $\mathrm{TNa}$ & $\mathrm{Na}^{+}$transport \\
\hline TVF & Tubular volumic flow \\
\hline Vcap & Capillary patch volume \\
\hline Vlum & Luminal patch volume \\
\hline
\end{tabular}

\section{References}

1. Ow, C.P.C.; Ngo, J.P.; Ullah, M.M.; Hilliard, L.M.; Evans, R.G. Renal hypoxia in kidney disease: Cause or consequence? Acta Physiol. 2018, 222, e12999. [CrossRef] [PubMed]

2. Singh, P.; Ricksten, S.-E.; Bragadottir, G.; Redfors, B.; Nordquist, L. Renal oxygenation and haemodynamics in acute kidney injury and chronic kidney disease. Clin. Exp. Pharmacol. Physiol. 2013, 40, 138-147. [CrossRef] [PubMed]

3. Steichen, C.; Giraud, S.; Bon, D.; Barrou, B.; Badet, L.; Salamé, E.; Kerforne, T.; Allain, G.; Roumy, J.; Jayle, C.; et al. Barriers and Advances in Kidney Preservation. BioMed Res. Int. 2018, 2018, 1-15. [CrossRef] [PubMed]

4. Cavaillé-Coll, M.; Bala, S.; Velidedeoglu, E.; Hernandez, A.; Archdeacon, P.; Gonzalez, G.; Neuland, C.; Meyer, J.; Albrecht, R. Summary of FDA Workshop on Ischemia Reperfusion Injury in Kidney Transplantation: FDA IRI Workshop. Am. J. Transplant. 2013, 13, 1134-1148. [CrossRef] [PubMed]

5. Legrand, M.; Mik, E.G.; Johannes, T.; Payen, D.; Ince, C. Renal Hypoxia and Dysoxia After Reperfusion of the Ischemic Kidney. Mol. Med. 2008, 14, 502-516. [CrossRef]

6. Leach, R.M.; Treacher, D.F. ABC of oxygen: Oxygen transport-2. Tissue hypoxia. BMJ 1998, 317, 1370-1373. [CrossRef]

7. Evans, R.G.; Gardiner, B.S.; Smith, D.W.; O'Connor, P.M. Intrarenal oxygenation: Unique challenges and the biophysical basis of homeostasis. Am. J. Physiol. Ren. Physiol. 2008, 295, F1259-F1270. [CrossRef]

8. Shanley, P.F.; Rosen, M.D.; Brezis, M.; Silva, P. Topography of Focal Proximal Tubular Necrosis After Ischemia With Reflow in the Rat Kidney. Am. J. Pathol. 1986, 122, 462-468.

9. Palm, F.; Nordquist, L. Renal tubulointerstitial hypoxia: Cause and consequence of kidney dysfunction. Clin. Exp. Pharmacol. Physiol. 2011, 38, 474-480. [CrossRef] 
10. Lee, C.-J.; Gardiner, B.S.; Ngo, J.P.; Kar, S.; Evans, R.G.; Smith, D.W. Accounting for oxygen in the renal cortex: A computational study of factors that predispose the cortex to hypoxia. Am. J. Physiol. Ren. Physiol. 2017, 313, F218-F236. [CrossRef]

11. Leichtweiss, H.-P.; Lübbers, D.W.; Weiss, C.H.; Baumgärtl, H.; Reschke, W. The oxygen supply of the rat kidney: Measurements of intrarenal $\mathrm{pO}_{2}$. Pflügers Arch. Eur. J. Physiol. 1969, 309, 328-349. [CrossRef] [PubMed]

12. Lubbers, D.W.; Baumgartl, H. Heterogeneities and profiles of oxygen pressure in brain and kidney as examples of the $\mathrm{PO}_{2}$ distribution in the living tissue. Kidney Int. 1997, 51, 372-380. [CrossRef] [PubMed]

13. Hansell, P.; Welch, W.J.; Blantz, R.C.; Palm, F. Determinants of kidney oxygen consumption and their relationship to tissue oxygen tension in diabetes and hypertension. Clin. Exp. Pharmacol. Physiol. 2013, 40, 123-137. [CrossRef] [PubMed]

14. Deng, A.; Miracle, C.M.; Lortie, M.; Satriano, J.; Gabbai, F.B.; Munger, K.A.; Thomson, S.C.; Blantz, R.C. Kidney oxygen consumption, carbonic anhydrase, and proton secretion. Am. J. Physiol. Ren. Physiol. 2006, 290, F1009-F1015. [CrossRef] [PubMed]

15. Evans, R.G.; Harrop, G.K.; Ngo, J.P.; Ow, C.P.C.; O'Connor, P.M. Basal renal $\mathrm{O}_{2}$ consumption and the efficiency of $\mathrm{O}_{2}$ utilization for $\mathrm{Na}^{+}$reabsorption. Am. J. Physiol. Ren. Physiol. 2014, 306, F551-F560. [CrossRef] [PubMed]

16. Evans, R.G.; Goddard, D.; Eppel, G.A.; O'Connor, P.M. Factors that render the kidney susceptible to tissue hypoxia in hypoxemia. Am. J. Physiol. Regul. Integr. Comp. Physiol. 2011, 300, R931-R940. [CrossRef]

17. Kaissling, B.; Dorup, J. Functional anatomy of the kidney. In Handbook of Experimental Pharmacology; Springer: Berlin/Heidelberg, Germany, 1995; Volume 177, pp. 1-66.

18. Blantz, R.C. Regulation Of Kidney Function And Metabolism: A Question Of Supply And Demand. Trans. Am. Clin. Clim. Assoc. 2007, 118, 23-43.

19. Baumgärtl, H.; Zimelka, W.; Lübbers, D.W. Evaluation of $\mathrm{PO}_{2}$ profiles to describe the oxygen pressure field within the tissue. Comp. Biochem. Physiol. Part A Mol. Integr. Physiol. 2002, 132, 75-85. [CrossRef]

20. Burke, T.J.; Malhotra, D.; Shapiro, J.I. Factors maintaining a pH gradient within the kidney: Role of the vasculature architecture. Kidney Int. 1999, 56, 1826-1837. [CrossRef]

21. Fry, B.C.; Layton, A.T. Oxygen transport in a cross section of the rat inner medulla: Impact of heterogeneous distribution of nephrons and vessels. Math. Biosci. 2014, 258, 68-76. [CrossRef]

22. Layton, A.T.; Vallon, V.; Edwards, A. Modeling oxygen consumption in the proximal tubule: Effects of NHE and SGLT2 inhibition. Am. J. Physiol. Ren. Physiol. 2015, 308, F1343-F1357. [CrossRef] [PubMed]

23. Olgac, U.; Kurtcuoglu, V. Renal oxygenation: Preglomerular vasculature is an unlikely contributor to renal oxygen shunting. Am. J. Physiol. Ren. Physiol. 2015, 308, F671-F688. [CrossRef] [PubMed]

24. Gardiner, B.S.; Smith, D.W.; O'Connor, P.M.; Evans, R.G. A mathematical model of diffusional shunting of oxygen from arteries to veins in the kidney. Am. J. Physiol. Ren. Physiol. 2011, 300, F1339-F1352. [CrossRef] [PubMed]

25. Gardiner, B.S.; Thompson, S.L.; Ngo, J.P.; Smith, D.W.; Abdelkader, A.; Broughton, B.R.S.; Bertram, J.F.; Evans, R.G. Diffusive oxygen shunting between vessels in the preglomerular renal vasculature: Anatomic observations and computational modeling. Am. J. Physiol. Ren. Physiol. 2012, 303, F605-F618. [CrossRef]

26. Lee, C.-J.; Ngo, J.P.; Kar, S.; Gardiner, B.S.; Evans, R.G.; Smith, D.W. A pseudo-three-dimensional model for quantification of oxygen diffusion from preglomerular arteries to renal tissue and renal venous blood. Am. J. Physiol. Ren. Physiol. 2017, 313, F237-F253. [CrossRef]

27. Lee, C.-J.; Gardiner, B.S.; Evans, R.G.; Smith, D.W. A model of oxygen transport in the rat renal medulla. Am. J. Physiol. Ren. Physiol. 2018, 315, F1787-F1811. [CrossRef]

28. Fry, B.C.; Edwards, A.; Sgouralis, I.; Layton, A.T. Impact of renal medullary three-dimensional architecture on oxygen transport. Am. J. Physiol. Ren. Physiol. 2014, 307, F263-F272. [CrossRef]

29. Chen, J.; Layton, A.T.; Edwards, A. A mathematical model of $\mathrm{O}_{2}$ transport in the rat outer medulla. I. Model formulation and baseline results. Am. J. Physiol. Ren. Physiol. 2009, 297, F517-F536. [CrossRef]

30. Zhang, W.; Edwards, A. Oxygen transport across vasa recta in the renal medulla. Am. J. Physiol. Heart Circ. Physiol. 2002, 283, H1042-H1055. [CrossRef]

31. Gullans, S.R.; Mandel, L. Coupling of energy to transport in proximal and distal nephron. In The Kidney: Physiology and Pathophysiology; Seldin, D.W., Giebisch, G., Eds.; Academic Press/Elsevier: Burlington, MA, USA, 2000; Volume 1, pp. 445-482. 
32. Layton, A.T. Modeling Transport and Flow Regulatory Mechanisms of the Kidney. ISRN Biomath. 2012, 2012, 1-18. [CrossRef]

33. Weinstein, A.M.; Weinbaum, S.; Duan, Y.; Du, Z.; Yan, Q.; Wang, T. Flow-dependent transport in a mathematical model of rat proximal tubule. Am. J. Physiol. Ren. Physiol. 2007, 292, F1164-F1181. [CrossRef] [PubMed]

34. Weinstein, A.M. A mathematical model of the rat nephron: Glucose transport. Am. J. Physiol. Ren. Physiol. 2015, 308, F1098-F1118. [CrossRef] [PubMed]

35. Layton, A.T.; Vallon, V.; Edwards, A. Predicted consequences of diabetes and SGLT inhibition on transport and oxygen consumption along a rat nephron. Am. J. Physiol. Ren. Physiol. 2016, 310, F1269-F1283. [CrossRef] [PubMed]

36. Brezis, M.; Rosen, S.; Silva, P.; Epstein, F.H. Selective vulnerability of the medullary thick ascending limb to anoxia in the isolated perfused rat kidney. J. Clin. Investig. 1984, 73, 182-190. [CrossRef] [PubMed]

37. Brezis, M.; Shanley, P.; Silva, P.; Spokes, K.; Lear, S.; Epstein, F.H.; Rosen, S. Disparate mechanisms for hypoxic cell injury in different nephron segments. Studies in the isolated perfused rat kidney. J. Clin. Investig. 1985, 76, 1796-1806. [CrossRef] [PubMed]

38. Cannata, N.; Corradini, F.; Merelli, E.; Tesei, L. Agent-based models of cellular systems. Methods Mol. Biol. 2012, 930, 399-426.

39. Railsback, S.; Lytinen, S.; Jackson, S. Agent-based simulation platforms: Review and development recommendations. Simulation 2006, 82, 609-623. [CrossRef]

40. Wilensky, U. NetLogo. (Center for Connected Learning and Computer-Based Modeling, Northwestern University, Evanston, IL) 1999. Available online: http://ccl.northwestern.edu/NetLogo/ (accessed on 5 December 2019).

41. Pfaller, W.; Seppi, T.; Ohno, A.; Giebisch, G.; Beck, F.X. Quantitative Morphology of Renal Cortical Structures during Compensatory Hypertrophy. Nephron Exp. Nephrol. 1998, 6, 308-319. [CrossRef]

42. Rasch, R.; Dørup, J. Quantitative morphology of the rat kidney during diabetes mellitus and insulin treatment. Diabetologia 1997, 40, 802-809. [CrossRef]

43. Matsui, K. Lymphatic Microvessels in the Rat Remnant Kidney Model of Renal Fibrosis: Aminopeptidase P and Podoplanin Are Discriminatory Markers for Endothelial Cells of Blood and Lymphatic Vessels. J. Am. Soc. Nephrol. 2003, 14, 1981-1989. [CrossRef]

44. Steinhausen, M.; Eisenbach, G.M.; Böttcher, W. High-frequency microcinematographic measurements on peritubular blood flow under control conditions and after temporary ischemia of rat kidneys. Pflügers Arch. Eur. J. Physiol. 1973, 339, 273-288. [CrossRef] [PubMed]

45. Gutierrez, G. The rate of oxygen release and its effect on capillary $\mathrm{O}_{2}$ tension: A mathematical analysis. Respir. Physiol. 1986, 63, 79-86. [CrossRef]

46. Féraille, E.; Doucet, A. Sodium-Potassium-Adenosinetriphosphatase-Dependent Sodium Transport in the Kidney: Hormonal Control. Physiol. Rev. 2001, 81, 345-418. [CrossRef] [PubMed]

47. Fromter, E.; Rumrich, G.; Ullrich, K.J.; Biophysik, M.-P.-I. Phenomenologic Description of $\mathrm{Na}^{+}, \mathrm{Ci}^{-}$and $\mathrm{HCO}_{3}$ Absorption from Proximal Tubules of the Rat Kidney. Plügers Arch. 1973, 343, 189-220. [CrossRef]

48. Schurek, H.; Jost, U.; Baumgartl, H.; Bertram, H.; Heckmann, U. Evidence for a preglomerular oxygen diffusion shunt in rat renal cortex. Am. J. Physiol. Ren. Physiol. 1990, 259, F910-F915. [CrossRef]

49. Emans, T.W.; Janssen, B.J.; Pinkham, M.I.; Ow, C.P.C.; Evans, R.G.; Joles, J.A.; Malpas, S.C.; Krediet, C.T.P.; Koeners, M.P. Exogenous and endogenous angiotensin-II decrease renal cortical oxygen tension in conscious rats by limiting renal blood flow: AngII and renal cortical oxygenation in conscious rats. J. Physiol. 2016, 594, 6287-6300. [CrossRef]

50. Layton, A.T. Recent advances in renal hypoxia: Insights from bench experiments and computer simulations. Am. J. Physiol. Ren. Physiol. 2016, 311, F162-F165. [CrossRef]

51. Layton, A.T.; Vallon, V.; Edwards, A. A computational model for simulating solute transport and oxygen consumption along the nephrons. Am. J. Physiol. Ren. Physiol. 2016, 311, F1378-F1390. [CrossRef]

52. Wilcox, C.S.; Palm, F.; Welch, W.J. Renal Oxygenation and Function of the Rat Kidney: Effects of Inspired Oxygen and Preglomerular Oxygen Shunting. In Oxygen Transport to Tissue XXXIV; Welch, W.J., Palm, F., Bruley, D.F., Harrison, D.K., Eds.; Springer: New York, NY, USA, 2013; Volume 765, pp. 329-334, ISBN 978-1-4614-4771-9. 
53. Welch, W.J.; Baumgärtl, H.; Lübbers, D.; Wilcox, C.S. Renal oxygenation defects in the spontaneously hypertensive rat: Role of AT1 receptors. Kidney Int. 2003, 63, 202-208. [CrossRef]

54. Welch, W.J.; Baumgärtl, H.; Lübbers, D.; Wilcox, C.S. Nephron $\mathrm{PO}_{2}$ and renal oxygen usage in the hypertensive rat kidney. Kidney Int. 2001, 59, 230-237. [CrossRef]

55. Dyson, A.; Bezemer, R.; Legrand, M.; Balestra, G.; Singer, M.; Ince, C. Microvascular and interstitial oxygen tension in the renal cortex and medulla studied in a 4-h rat model of LPS-induced endotoxemia. Shock 2011, 36, 83-89. [CrossRef] [PubMed]

56. Johannes, T.; Mik, E.G.; Ince, C. Dual-wavelength phosphorimetry for determination of cortical and subcortical microvascular oxygenation in rat kidney. J. Appl. Physiol. 2006, 100, 1301-1310. [CrossRef] [PubMed]

57. Evans, R.G.; Goddard, D.; Eppel, G.A.; O'Connor, P.M. Stability of tissue $\mathrm{PO}_{2}$ in the face of altered perfusion: A phenomenon specific to the renal cortex and independent of resting renal oxygen consumption: Renal cortical oxygenation. Clin. Exp. Pharmacol. Physiol. 2011, 38, 247-254. [CrossRef] [PubMed]

58. Leong, C.; Anderson, W.P.; O'Connor, P.M.; Evans, R.G. Evidence that renal arterial-venous oxygen shunting contributes to dynamic regulation of renal oxygenation. Am. J. Physiol. Ren. Physiol. 2007, 292, F1726-F1733. [CrossRef] [PubMed]

59. Steinhausen, M.; Endlich, K.; Wiegman, D. Glomerular blood flow. Kidney Int. 1990, 38, 769-784. [CrossRef] [PubMed]

60. Pittman, R.N. Oxygen Transport in the Microcirculation and Its Regulation. Microcirculation 2013, $20,117-137$. [CrossRef] [PubMed]

61. Sasaki, N.; Horinouchi, H.; Ushiyama, A.; Minamitani, H. A New Method for Measuring the Oxygen Diffusion Constant and Oxygen Consumption Rate of Arteriolar Walls. Keio J. Med. 2012, 61, 57-65. [CrossRef]

62. Vadapalli, A.; Pittman, R.N.; Popel, A.S. Estimating oxygen transport resistance of the microvascular wall. Am. J. Physiol. Heart Circ. Physiol. 2000, 279, H657-H671. [CrossRef]

63. Diez, J.; Hannaert, P.; Garay, R. Kinetic study of Na+-K+ pump in erythrocytes from essential hypertensive patients. Am. J. Physiol. Heart Circ. Physiol. 1987, 252, H1-H6. [CrossRef]

64. Moll, W. The influence of hemoglobin diffusion on oxygen uptake and release by red cells. Respir. Physiol. 1968, 6, 1-15. [CrossRef]

65. Clark, A.; Federspiel, W.J.; Clark, P.A.; Cokelet, G.R. Oxygen delivery from red cells. Biophys. J. 1985, 47, 171-181. [CrossRef]

66. Pallone, T.; Zhang, Z.; Rhinehart, K. Physiology of the renal medullary microcirculation. Am. J. Physiol. Ren. Physiol. 2003, 284, F253-F266. [CrossRef] [PubMed]

67. Larsen, E.H.; Mobjerg, N.; Sorensen, J.N. Fluid transport and ion fluxes in mammalian kidney proximal tubule: A model analysis of isotonic transport. Acta Physiol. 2006, 187, 177-189. [CrossRef] [PubMed]

68. Brand, M. The efficiency and plasticity of mitochondrial energy transduction. Biochem. Soc. Trans. 2005, 33, 897-904. [CrossRef]

69. Stucki, J.W. The Optimal Efficiency and the Economic Degrees of Coupling of Oxidative Phosphorylation. Eur. J. Biochem. 1980, 109, 269-283. [CrossRef]

70. Evans, R.G.; Eppel, G.A.; Michaels, S.; Burke, S.L.; Nematbakhsh, M.; Head, G.A.; Carroll, J.F.; O'Connor, P.M. Multiple mechanisms act to maintain kidney oxygenation during renal ischemia in anesthetized rabbits. Am. J. Physiol. Ren. Physiol. 2010, 298, F1235-F1243. [CrossRef]

71. Kaminski, J.; Delpech, P.-O.; Kaaki-Hosni, S.; Promeyrat, X.; Hauet, T.; Hannaert, P. Oxygen Consumption by Warm Ischemia-Injured Porcine Kidneys in Hypothermic Static and Machine Preservation. J. Surg. Res. 2019, 242, 78-86. [CrossRef]

72. Grosenick, D.; Cantow, K.; Arakelyan, K.; Wabnitz, H.; Flemming, B.; Skalweit, A.; Ladwig, M.; Macdonald, R.; Niendorf, T.; Seeliger, E. Detailing renal hemodynamics and oxygenation in rats by a combined near-infrared spectroscopy and invasive probe approach. Biomed. Opt. Express 2015, 6, 309. [CrossRef]

73. Whitehouse, T.; Stotz, M.; Taylor, V.; Stidwill, R.; Singer, M. Tissue oxygen and hemodynamics in renal medulla, cortex, and corticomedullary junction during hemorrhage-reperfusion. Am. J. Physiol. Ren. Physiol. 2006, 291, F647-F653. [CrossRef]

74. Ngo, J.P.; Lankadeva, Y.R.; Zhu, M.Z.L.; Martin, A.; Kanki, M.; Cochrane, A.D.; Smith, J.A.; Thrift, A.G.; May, C.N.; Evans, R.G. Factors that confound the prediction of renal medullary oxygenation and risk of acute kidney injury from measurement of bladder urine oxygen tension. Acta Physiol. 2019, 227, e13294. [CrossRef] 
75. Lankadeva, Y.R.; Kosaka, J.; Evans, R.G.; Bellomo, R.; May, C. Urinary Oxygenation as a Surrogate Measure of Medullary Oxygenation During Angiotensin II Therapy in Septic Acute Kidney Injury. Crit. Care Med. 2018, 46, e41-e48. [CrossRef] [PubMed]

76. Evans, R.G.; Ow, C.P.C. Heterogeneity of renal cortical oxygenation: Seeing is believing. Kidney Int. 2018, 93, 1278-1280. [CrossRef] [PubMed]

77. Garg, L.C.; Mackie, S.; Tisher, C.C. Effect of low potassium-diet on NaK-ATPase in rat nephron segments. Pflügers Arch. Eur. J. Physiol. 1982, 394, 113-117. [CrossRef] [PubMed]

78. Gullans, S.R. Metabolic basis of ion transport. In The Kidney; Brenner, B.M., Rector, F.C., Eds.; Saunders: Philadelphia, PA, USA, 2000.

79. Soltoff, S.P. ATP and the Regulation of Renal Cell Function. Ann. Rev. Physiol. 1986, 48, 9-31. [CrossRef] [PubMed]

80. Guder, W.G.; Ross, B.D. Enzyme distribution along the nephron. Kidney Int. 1984, 26, 101-111. [CrossRef]

81. Goldman, D. Theoretical Models of Microvascular Oxygen Transport to Tissue. Microcirculation 2008, 15, 795-811. [CrossRef]

82. McGuire, B.J.; Secomb, T.W. A theoretical model for oxygen transport in skeletal muscle under conditions of high oxygen demand. J. Appl. Physiol. 2001, 91, 2255-2265. [CrossRef]

83. Piiper, J.; Scheid, P. Modeling oxygen availability to exercising muscle. Respir. Physiol. 1999, 118, 95-101. [CrossRef]

84. Eggleton, C.D.; Vadapalli, A.; Roy, T.K.; Popel, A.S. Calculations of intracapillary oxygen tension distributions in muscle. Math. Biosci. 2000, 167, 123-143. [CrossRef]

85. Groebe, K. An Easy-to-Use Model for $\mathrm{O}_{2}$ Supply to Red Muscle. Validity of Assumptions, Sensitivity to Errors in Data. Biophys. J. 1995, 68, 1246-1269. [CrossRef]

86. Fletcher, J.E. On facilitated oxygen diffusion in muscle tissues. Biophys. J. 1980, 29, 437-458. [CrossRef]

87. Ivanov, K.; Kalinina, M.; Levkovich, Y. Blood flow velocity in capillaries of brain and muscles and its physiological significance. Microvasc. Res. 1981, 22, 143-155. [CrossRef]

88. Brezis, M.; Rosen, S. Hypoxia of the Renal Medulla-Its Implications for Disease. N. Engl. J. Med. 1995, 332, 647-655. [CrossRef] [PubMed]

89. Ellsworth, M.L.; Ellis, C.G.; Sprague, R.S. Role of erythrocyte-released ATP in the regulation of microvascular oxygen supply in skeletal muscle. Acta Physiol. 2016, 216, 265-276. [CrossRef]

90. Sridharan, M.; Sprague, R.S.; Adderley, S.P.; Bowles, E.A.; Ellsworth, M.L.; Stephenson, A.H. Diamide decreases deformability of rabbit erythrocytes and attenuates low oxygen tension-induced ATP release. Exp. Biol. Med. 2010, 235, 1142-1148. [CrossRef]

91. Wang, B.; Scott, R.C.; Pattillo, C.B.; Prabhakarpandian, B.; Sundaram, S.; Kiani, M.F. Microvascular transport model predicts oxygenation changes in the infarcted heart after treatment. Am. J. Physiol. Heart Circ. Physiol. 2007, 293, H3732-H3739. [CrossRef]

92. Hirakawa, Y.; Mizukami, K.; Yoshihara, T.; Takahashi, I.; Khulan, P.; Honda, T.; Mimura, I.; Tanaka, T.; Tobita, S.; Nangaku, M. Intravital phosphorescence lifetime imaging of the renal cortex accurately measures renal hypoxia. Kidney Int. 2018, 93, 1483-1489. [CrossRef]

93. Hirakawa, Y.; Yoshihara, T.; Kamiya, M.; Mimura, I.; Fujikura, D.; Masuda, T.; Kikuchi, R.; Takahashi, I.; Urano, Y.; Tobita, S.; et al. Quantitating intracellular oxygen tension in vivo by phosphorescence lifetime measurement. Sci. Rep. 2016, 5, 17838. [CrossRef]

94. Egginton, S.; Gaffney, E. Experimental Physiology—Review Article: Tissue capillary supply—It's quality not quantity that counts! Optimizing peripheral oxygen transport. Exp. Physiol. 2010, 95, 971-979. [CrossRef]

95. Chade, A.R. Renal Vascular Structure and Rarefaction. In Comprehensive Physiology; Terjung, R., Ed.; John Wiley \& Sons, Inc.: Hoboken, NJ, USA, 2013; ISBN 978-0-470-65071-4.

96. Basile, D.P.; Anderson, M.D.; Sutton, T.A. Pathophysiology of Acute Kidney Injury. In Comprehensive Physiology; Terjung, R., Ed.; John Wiley \& Sons, Inc.: Hoboken, NJ, USA, 2012; ISBN 978-0-470-65071-4.

97. Basile, D.P.; Donohoe, D.L.; Roethe, K.; Mattson, D.L. Chronic renal hypoxia after acute ischemic injury: Effects of L-arginine on hypoxia and secondary damage. Am. J. Physiol. Ren. Physiol. 2003, 284, F338-F348. [CrossRef]

98. Matsumoto, M. Hypoperfusion of Peritubular Capillaries Induces Chronic Hypoxia before Progression of Tubulointerstitial Injury in a Progressive Model of Rat Glomerulonephritis. J. Am. Soc. Nephrol. 2004, 15, 1574-1581. [CrossRef] [PubMed] 
99. Kaminski, J.; Hannaert, P.; Kasil, A.; Thuillier, R.; Leize, E.; Delpy, E.; Steichen, C.; Goujon, J.M.; Zal, F.; Hauet, T. Efficacy of the natural oxygen transporter $\mathrm{HEMO}_{2}$ life ${ }^{\circledR}$ in cold preservation in a preclinical porcine model of donation after cardiac death. Transpl. Int. 2019, 32, 985-996. [CrossRef] [PubMed]

100. Suzuki, N.; Yamamoto, M. Roles of renal erythropoietin-producing (REP) cells in the maintenance of systemic oxygen homeostasis. Pflügers Arch. Eur. J. Physiol. 2016, 468, 3-12. [CrossRef] [PubMed]

101. Jelkmann, W. Regulation of erythropoietin production: Erythropoietin production. J. Physiol. 2011, 589, 1251-1258. [CrossRef]

102. Hernandez, A.; Le Rolle, V.; Ojeda, D.; Baconnier, P.; Fontecave-Jallon, J.; Guillaud, F.; Grosse, T.; Moss, R.; Hannaert, P.; Thomas, S. Integration of detailed modules in a core model of body fluid homeostasis and blood pressure regulation. Prog. Biophys. Mol. Biol. 2011, 107, 169-182. [CrossRef]

103. Guillaud, F.; Hannaert, P. A Computational Model of the Circulating Renin-Angiotensin System and BloodPressure Regulation. Acta Biotheor. 2010, 58, 143-170. [CrossRef]

(C) 2019 by the authors. Licensee MDPI, Basel, Switzerland. This article is an open access article distributed under the terms and conditions of the Creative Commons Attribution (CC BY) license (http://creativecommons.org/licenses/by/4.0/). 